\title{
Experimental and nonlinear finite element analysis of shear behaviour of reinforced concrete beams
}

\author{
Touhami Tahenni ${ }^{1, *}$, Farid Bouziadi², Bensaid Boulekbache ${ }^{2}$, Sofiane Amziane ${ }^{3}$ \\ ${ }^{1}$ Laboratory of Acoustic and Civil Engineering, Djilali Bounaama University of Khemis Miliana, \\ Khemis Miliana, Algeria. \\ ${ }^{2}$ Laboratory of Materials Sciences and Environment, Hassiba Benbouali University of Chlef, Chlef, \\ Algeria. \\ ${ }^{3}$ University of Clermont Auvergne, Institut Pascal, UMR 6602, 63174 Aubière, France. \\ *Corresponding author: touhami_tahenni@yahoo.fr (T. Tahenni)
}

\begin{abstract}
This paper presents an experimental investigation and nonlinear finite element analysis (NLFEA), using the numerical analysis tool ANSYS $^{\odot}$, carried out on the shear and diagonal cracking effect on the behaviour of reinforced-concrete (RC) beams made of normal strength concrete (NSC) and highstrength concrete (HSC), with and without transverse reinforcement. Beams were tested using fourpoint bending, by means of digital image correlation (DIC). In the experimental setup, the shear zone was digitised using a high-resolution camera to assess the deformation of concrete in the compression zone and to measure the diagonal crack widths. The results show that transverse reinforcement does efficiently control the diagonal crack width, increases the shear capacity of the beams, shifts the mode failure from shear to flexure, and significantly improves the ductility of beams in the ultimate state particularly when using HSC, given the better quality of the bond developed in the concrete with steel reinforcement. The values of ultimate shear strength obtained experimentally were compared to the corresponding empirical values available in the literature. Furthermore, detailed 3D finite element analysis (FEA) was used to predict the load-deflection response, the ultimate load, the cracking load, the ultimate deflection, the maximum diagonal crack widths and the cracks patterns in RC beams. The difference values between the numerical and experimental values range from -11.08 to $+0.6 \%$, from -2.02 to $-0.52 \%$ and from -13.27 to $-1.01 \%$ for cracking load, for ultimate load and for ultimate midspan deflection, respectively. The ratio of the predicted to experimental maximum diagonal crack width for the beams ranged between 0.95 and 1.06. Also, a good agreement between the experimental and numerical crack patterns was achieved. Consequently, the FEA model is able to predict the shear response of RC beams with a good accuracy.
\end{abstract}

Keywords: Shear; Diagonal cracking; Compressive strength; Transverse reinforcement; Ductility; Finite element analysis. 


\section{Introduction}

An extensive body of literature is available on the shear behaviour of RC beams, from both analytical and experimental stand points. However, no methodical study has previously been performed for the calculation and designing of RC elements undergoing shear loading. This deficiency is addressed in various international codes and technical documents, the contents of which vary extremely widely. This clearly demonstrates the disparity of international opinions on the shear behaviour of concrete. It can be said that there are negligible differences in the approaches to calculating flexion in RC elements. However, as yet, debate continues as to the effect of shear, and consensus appears a long way off. Also, at least at the present time, there is no theory able to explain the majority of aspects of shear behaviour. The existing formulas are semi-empirical, based on observations of ordinary concrete. Generally, HSC is more brittle; this difference of behaviour, compared to NSC, means that the semi-empirical models need to be developed through experimentation on HSC [1-4].

In current practice, many calculation parameters and equations in the design codes are derived mostly from experimental research programs for on concretes whose compressive strength does not exceed $40 \mathrm{MPa}$. Therefore, it is reasonable to verify the validity of these equations on concretes whose strength exceeds $40 \mathrm{MPa}$, as is the case for HSC [5].

In a $\mathrm{RC}$ beam, the total ultimate shear force $\mathrm{V}_{\mathrm{u}}$ is countered by the shear contributions across the compression zone $\mathrm{V}_{\mathrm{cy}}$, the aggregate interlocking $\mathrm{V}_{\mathrm{ay}}$, the dowel action effect of the longitudinal steel $\mathrm{V}_{\mathrm{d}}$ and the transverse reinforcement $\mathrm{V}_{\mathrm{s}}[6,7]$.

Note that the contribution of each component has not been accurately established. Taylor [7] concluded that the three components of the concrete contribute to ultimate shear resistance for concrete compressive strength ranging from 26 to $49 \mathrm{MPa}$, as follows: the compression zone $\mathrm{V}_{\mathrm{cy}}=20$ to $40 \%$, the aggregate interlocking $\mathrm{V}_{\mathrm{ay}}=33$ to $50 \%$ and the dowel action effect $\mathrm{V}_{\mathrm{d}}=15$ to $25 \%$. On the other hand, for HSC beams whose strength is within the range of 40 to $110 \mathrm{MPa}$, Sarkar et al. [6] suggested the following contribution: the compression zone $\mathrm{V}_{\mathrm{cy}}=13$ to $17 \%$, the aggregate interlocking $\mathrm{V}_{\text {ay }}=34$ to $40 \%$ and the dowel action effect $\mathrm{V}_{\mathrm{d}}=43$ to $53 \%$. In HSC, it has been reported that the aggregate interlocking contribution to the shear strength $\left(\mathrm{V}_{\mathrm{ay}}\right)$ is considerably reduced $[2,4,8,9]$, compared to that in NSC. This is thought to be due to the nature of diagonal cracking, straight and trans-granular with smooth crack faces as compared to the one in NSC which is rather inter-granular with rough crack faces $[4,5,10,11]$. This may be caused by the nature of the cement, which is highly resistant in HSC compared to NSC. However, the dowel action effect of the longitudinal steel $\left(\mathrm{V}_{\mathrm{d}}\right)$ contributing to the shear strength of HSC better when compared to NSC. This is the result of the better bond between the longitudinal reinforcement and HSC [12]. It should be reported that these three shear components $\left(\mathrm{V}_{\mathrm{ay}}, \mathrm{V}_{\mathrm{cy}}, \mathrm{V}_{\mathrm{d}}\right)$ and their interactions have not yet been clearly defined, and no analytical method explains them rationally [6]. 
Digital image correlation (DIC) is an optical method that uses tracking and image registration for accurate 2D and 3D measurements of changes in images. This method is often used to measure fullfield displacement and strain, and it is widely applied in many areas of science and engineering, with new applications being found all the time. The greatest benefit of DIC is the high accuracy of the results, for which reason, many researchers have made use of it. Applications of DIC include measuring tensile strength and 3D displacements [13,14], analysis of the fracture mechanism of steel fibre RC in tensile splitting [15], measurement of crack widths in concrete beams [16-18], study of steel corrosion [19] and flexural strengthening of concrete beams using FRP [20].

In addition, various numerical programmes have studied the behaviour of $\mathrm{RC}$ members under bending, using NLFEA [21-24]. The FE modelling tools ANSYS $^{\odot}$ or ABAQUS ${ }^{\odot}$ are used to predict the behaviour of RC structures. Generally, it has been found that the predicted FE results correspond closely to the data measured in experimental tests. However, these researchers have not used FEA software to calculate the crack widths.

This paper presents an experimental study of sixteen RC beams made of NSC and HSC under shear, evaluating the shear capacity of the tested beams and comparing the results with the different models taken from earlier published works, to examine the diagonal cracking behaviour in terms of appearance and development, and measure the crack opening and the deformation of concrete using DIC. Furthermore, the shear behaviour of RC beams using the NLFEA ANSYS ${ }^{\odot}$ program, the maximum diagonal crack widths and the crack patterns are investigated.

\section{Experimental program}

\subsection{Materials and mix proportions of concrete}

The materials used in the concrete mixtures are ordinary Portland cement CEM I $52.5 \mathrm{~N}$, river rounded sand $(0 / 4 \mathrm{~mm})$, crushed gravel $(4 / 15 \mathrm{~mm})$, limestone fillers and water. For HSC, blast furnace slag is used in a proportion of $10 \%$ by weight of cement to its economic and environmental improvements [25], and high range water reducing admixture in proportion of $2.5 \%$ by weight of cement. The ingredients of the concrete mix were mixed in a drum mixer with a horizontal axis. Table 1 shows the mixture proportion for the concretes tested.

Table1. Mixture proportions of concrete $\left(\mathrm{kg} / \mathrm{m}^{3}\right)$.

\begin{tabular}{llllllllll}
\hline Concrete & Cement & Slag & $\begin{array}{l}\text { Limestone } \\
\text { filler }\end{array}$ & Sand & Gravel & Water & Admixture & W/C & $\begin{array}{l}\text { Slump } \\
(\mathrm{mm})\end{array}$ \\
\hline NSC & 275 & $/$ & 55 & 860 & 945 & 165 & $/$ & 0.60 & 120 \\
HSC & 382 & 38.2 & 90 & 700 & 1029 & 146 & 9.56 & 0.38 & 150 \\
\hline
\end{tabular}




\subsection{Material properties}

\subsubsection{Concrete}

The compressive strength of the NSC and HSC used in making the beams with and without transverse reinforcement was measured by crushing cylindrical concrete specimens $110 \times 220 \mathrm{~mm}$, according to EN 12390-3 [26]. Also, splitting tensile strength was performed on the same dimensions according to EN 12390-6 [27]. An extensometer was used to measure longitudinal compressive strains in order to assess the Young's modulus of the concrete in according with ASTM C469 [28]. The testing machine used delivered a controlled load for the compressive test with a $3000 \mathrm{kN}$ capacity load cell. The mechanical properties of concrete obtained are summarised in Table 2.

Table2. Mechanical properties of concretes.

\begin{tabular}{cccc}
\hline Concrete & $\begin{array}{c}\text { Compressive strength } \\
\mathrm{f}_{\mathrm{c}}(\mathrm{MPa})\end{array}$ & $\begin{array}{c}\text { Splitting tensile strength } \\
\mathrm{f}_{\mathrm{t}}(\mathrm{MPa})\end{array}$ & $\begin{array}{c}\text { Elastic modulus } \\
\mathrm{E}_{\mathrm{c}}(\mathrm{GPa})\end{array}$ \\
\hline $\mathrm{NSC}$ & 32 & 3.2 & 38.7 \\
$\mathrm{HSC}$ & 65 & 5.9 & 42.3 \\
\hline
\end{tabular}

\subsubsection{Steel}

The longitudinal reinforcement of the beams comprises $2 \varnothing 10$ in the tension zone and $2 \varnothing 8$ in the compression zone. The transverse reinforcement was provided by stirrups, $6 \mathrm{~mm}$ in diameter and spaced a constant distance $100 \mathrm{~mm}$ apart.

The high-grade steel longitudinal reinforcement, $10 \mathrm{~mm}$ in diameter, is placed in the tension zone and is characterised by a direct tension machine with a $500 \mathrm{kN}$ load cell to determine the mechanical properties: Young's modulus and elastic limit. The current deformations are measured with an extensometer with $12.5 \mathrm{~mm}$ gauge length. The test results show a Young's modulus of $204 \mathrm{GPa}$ and an elastic limit of $500 \mathrm{MPa}$.

\subsection{Beam specimens and testing procedure}

This experimental programme involves testing sixteen RC beams with identical rectangular crosssections of $100 \times 150 \mathrm{~mm}$. The single span length is $900 \mathrm{~mm}$ and the shear span length is $300 \mathrm{~mm}$. The major test variables are the concrete compressive strength and the transverse reinforcement ratio. The beams were divided into four series, each consisting of four specimens. The first series was made of normal strength concrete, without any transverse reinforcement, represented as NSC-S0. The second is reinforced transversally and made of normal strength concrete, written as NSC-S1. The third series did not contain any transverse reinforcement and was made of high strength concrete, notated HSC-S0. The fourth series is transversally reinforced high strength concrete (HSC-S1). All beams were vibrated with a vibrating needle. After casting, the beams were covered with wet burlap until demoulding after 24 hours, and were stored in the laboratory until the day of testing. Fig. 1 illustrates the steps following in manufacturing the tested beams. 


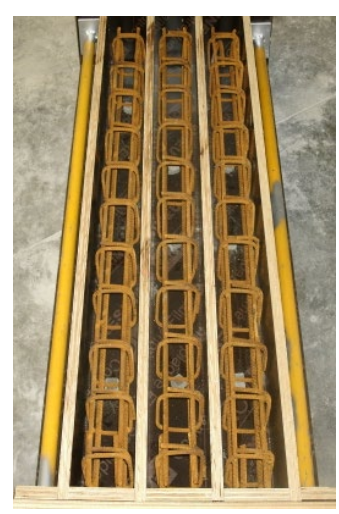

(a) Reinforcement.

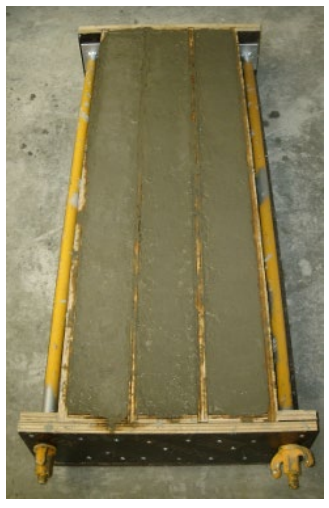

(b) Casting.

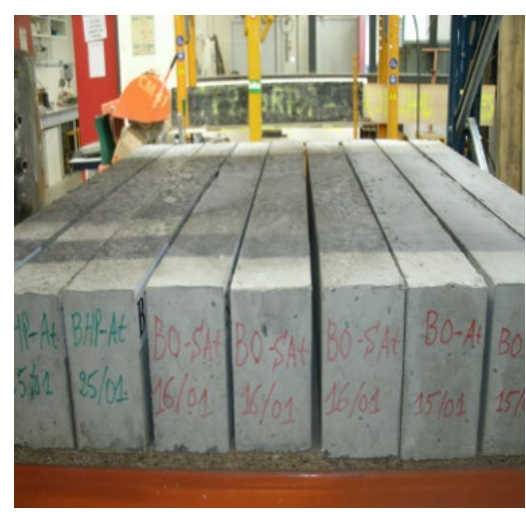

(c) Storage.

Fig. 1. Manufacture of RC beams.

The RC beams were tested under four-point bending using a two-column machine with a $250 \mathrm{kN}$ capacity at a rate of $0.01 \mathrm{~mm} / \mathrm{s}$, as shown in Figs. 2 and 3. The loading applied is monotone static. One LVDT is placed in the tension zone and at mid-span of each beam to measure the deflection history.

The beams were equipped with $5 \mathrm{~mm}$-long electrical strain gauges, at the centre of the tensile longitudinal reinforcement and at mid-height of two stirrups located in second and third position relative to the first stirrups. Prior to testing, the surface of the shear zone between the support and the loading point of the beam were polished, as shown in Fig. 3. A highly sensitive camera was also used to capture the appearance and development of diagonal cracks in the shear zone (Fig. 3). The system tracks the movement of the points applied beforehand on the surface of the tested beam. The digital images are recorded and analysed by Gom-Aramis software [29], to measure the deformations of compressed concrete and the diagonal crack widths (Fig. 4).

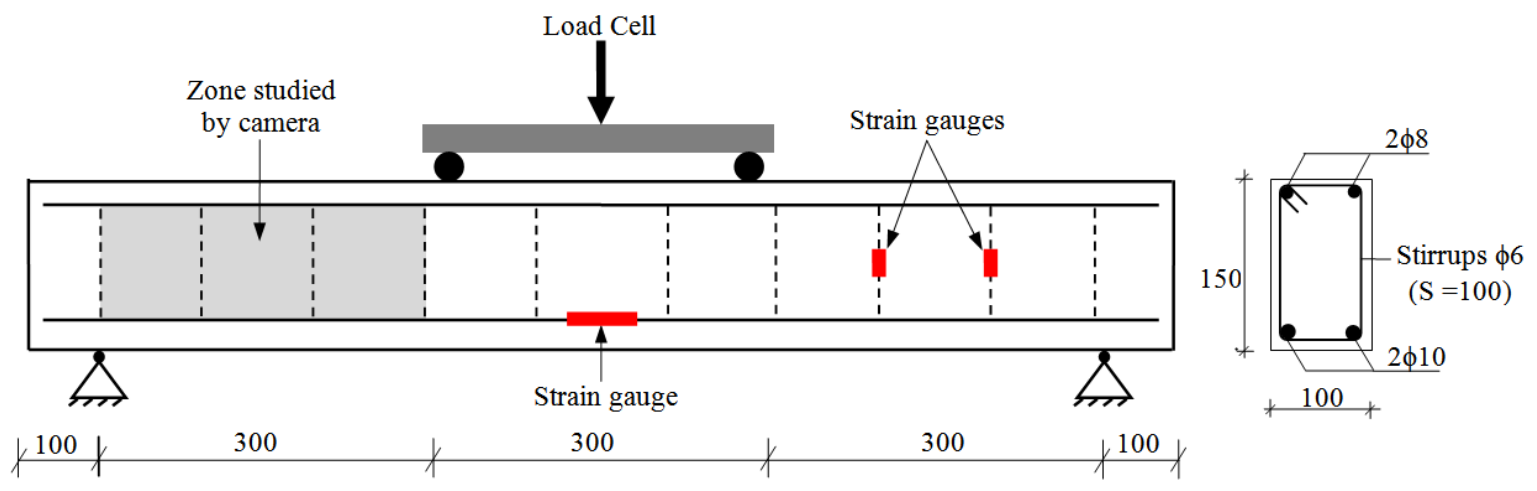

Fig. 2.Reinforcement of tested beams (dimensions in $\mathrm{mm}$ ). 


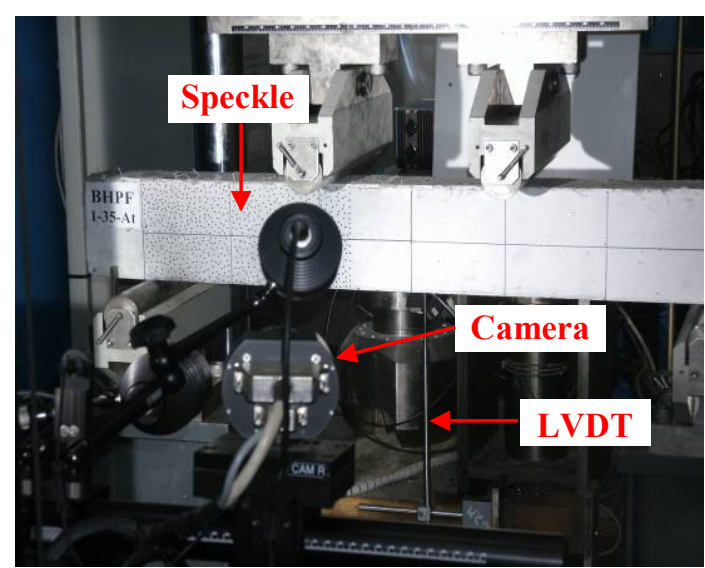

Fig. 3. Four-point bending test.

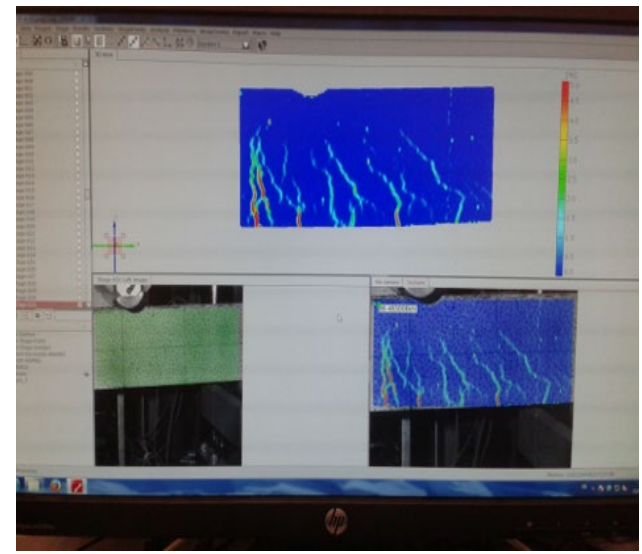

Fig. 4. Image analysis by Aramis software.

\section{Test results and discussion}

\subsection{Apparition of cracks in beam and failure modes}

The flexural cracks first develop in the tension zone of the beams. Before the occurrence of the inclined cracks, the effect of transverse reinforcement can be ignored. When loading increases, from 60 to $70 \%$ of ultimate load of NSC and HSC beams respectively, diagonal cracks appear within the shear zone in the directions both of the support and of the load application. Two types of diagonal cracks are observed; those ones initiated by a flexural crack and those induced independently of flexural cracks. The presence of the transverse reinforcement efficiently restricts the diagonal crack widths and prevents shear failure. In the presence of transverse reinforcement, failure occurs by flexion through crushing of the compressed concrete in the zone of maximum moment, and subsequently, the flexural cracks push the neutral axis sufficiently towards the top of the beam for failure to occur (Fig. 5(a)). In very few cases with HSC beams, the diagonal crack penetrates into the compression zone at the point of loading and causes crushing of the concrete as shown in Fig. 5(c). This mode of failure is known as shear-compression.

No cracks developed lengthwise along the longitudinal reinforcement in the beams with transverse reinforcement, while diagonal cracks increased. The transverse reinforcement confines the concrete around the longitudinal steel elements and also prevents bond failure along the longitudinal bars. This is especially true for HSC, which develops a better bond with the reinforcing steels. The enhancing of the compressive strength of concrete from 32 to $65 \mathrm{MPa}$ increases the number of diagonal cracks, indicating a better bond between the concrete and the transverse stirrups in the highstrength concrete beams (HSC-S1).

The failure of beams without transverse reinforcement (NSC-S0 and HSC-S0) is characterised by the development of one diagonal crack within the shear zone, in the direction of support and loading point, independently of the flexural crack, and by disconnection of the concrete below the longitudinal tension reinforcement. When this crack becomes sufficiently large, the failure occurs by diagonal fracture of the beam, as shown in Figs. 5(b) and (d). This mode of failure can be expected in the 
absence of the transverse reinforcement, which was designed on the basis of shear criteria. In some cases of HSC beams, the concrete crushes at the loading point in brittle and explosive mode simultaneously with the diagonal failure.

The two types of concrete present almost an identical slope of the diagonal cracks: approximately $45^{\circ}$ from the longitudinal axis of the beam. The trajectory of the diagonal cracks grows around the aggregate particles in the beams made of NSC. For HSC beams, this trajectory appears to be straight, and the crack traverses the aggregate particles. With this type of cracking, the contribution of aggregate interlocking to the shear resistance of HSC is decreased, by comparison to NSC. It should be noted that this inner parameter of shear resistance has not been rationally identified as have the other parameters (namely the contribution of the compressed zone of the concrete and the dowel action effect of the longitudinal steel).

The presence of transverse reinforcement seems to change the mode of failure, from diagonal shear failure observed in the series of beams without transverse reinforcement (beams NSC-S0 and HSC-S0), which were particularly sudden and explosive in the case of HSC, to more flexible, ductile failure by flexion in the series of beams which are transversely reinforced (NSC-S1 and HSC-S1). Fig. 5 shows the modes of failure of four series of the tested beams.
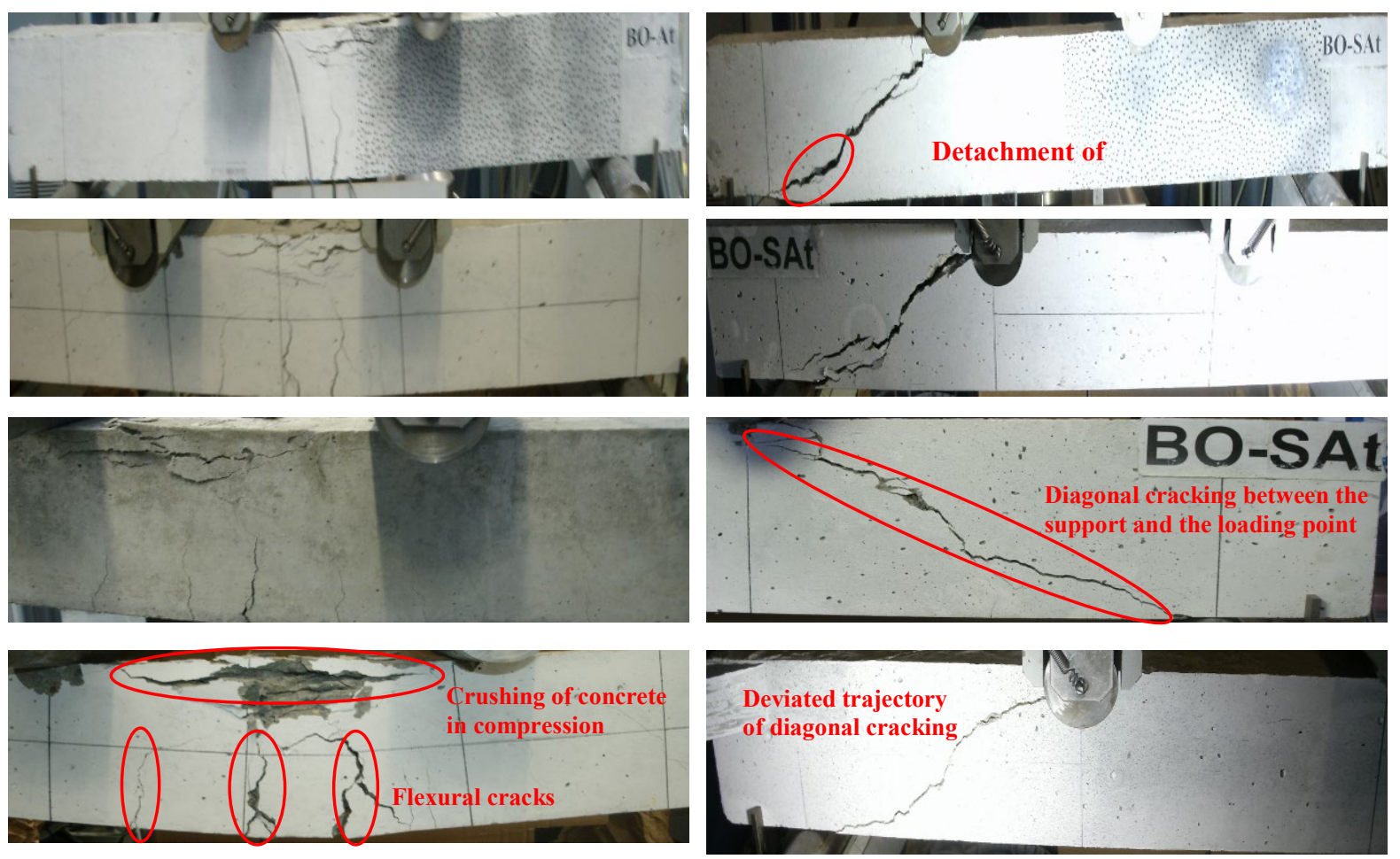

(a) Failure of series NSC-S1 beams (with stirrups)

(b) Failure of series NSC-S0 beams (without stirrups)
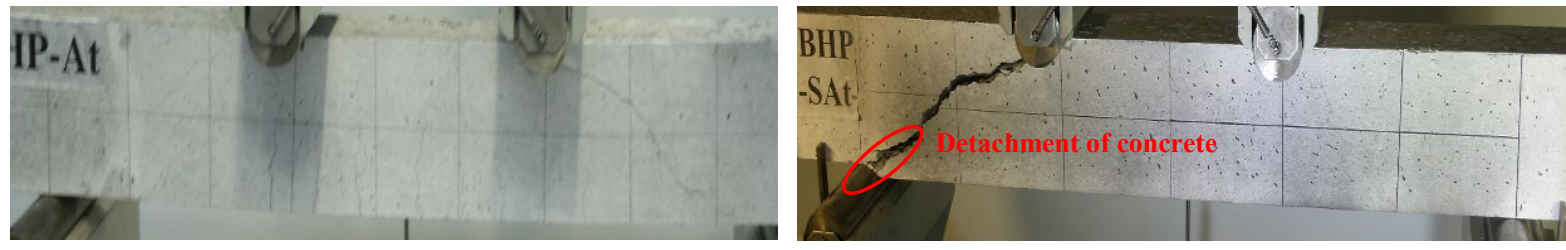

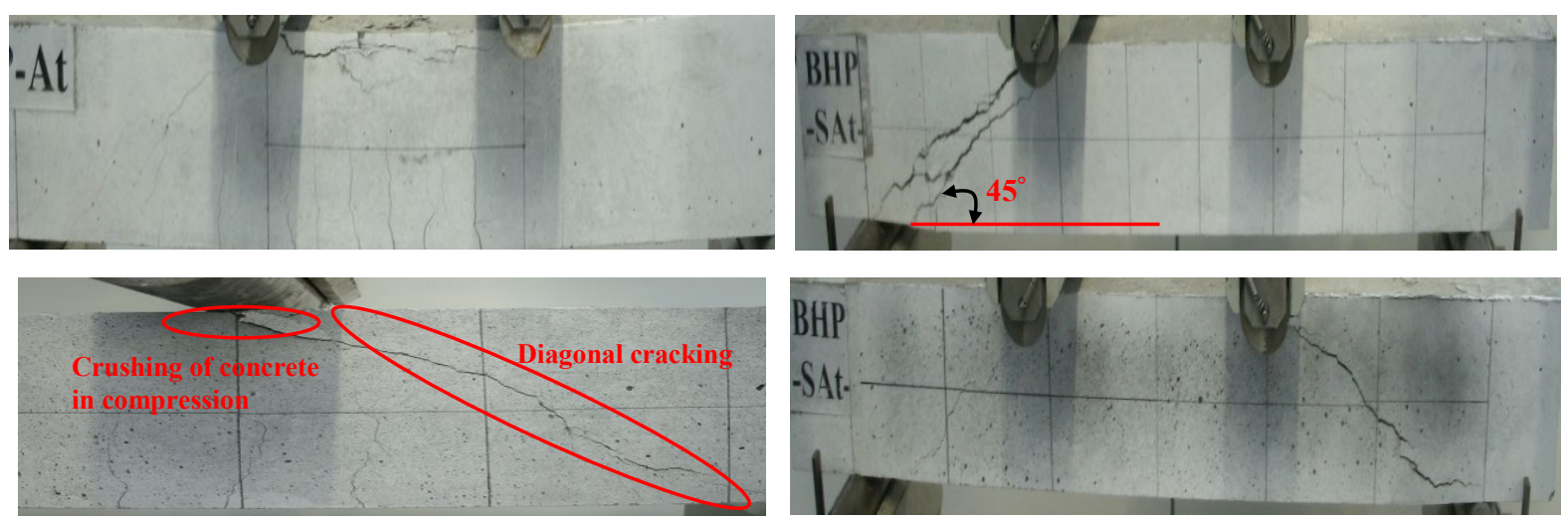

(c) Failure of series HSC-S1 beams (with stirrups)

(d) Failure of series HSC-S0 beams (without stirrups)

Fig. 5. Different modes of failure of the tested beams.

For each beam tested, Table 3 indicates the first crack load $\left(\mathrm{P}_{\text {cr }}\right)$, the diagonal cracking load $\left(\mathrm{P}_{\mathrm{d}}\right)$, the ultimate load $\left(\mathrm{P}_{\mathrm{u}}\right)$ and the ratio $\mathrm{P}_{\mathrm{u}} / \mathrm{P}_{\mathrm{d}}$. The beams for which no value of the first crack load and the diagonal cracking load are given have not been analysed by Aramis software [29] only the ultimate load and mid-span deflection were measured for these beams. The study parameters illustrated in Table 3 are the compressive strength of concrete $\left(f_{c}\right)$ to simulate the type of concrete, and the transverse reinforcement ratio $\left(\rho_{\mathrm{w}}\right)$ to simulate the presence or absence of transverse reinforcement. The shear-span/effective depth ratio $(\mathrm{a} / \mathrm{d})$ and the longitudinal reinforcement ratio $\left(\rho_{\mathrm{s}}\right)$ were considered constant in the sixteen test beams $\left(\mathrm{a} / \mathrm{d}=2.2\right.$ and $\left.\rho_{\mathrm{s}}=1.16 \%\right)$.

Table 3. Ultimate load and cracking loads of tested beams.

\begin{tabular}{lllllll}
\hline Beams & $\mathrm{f}_{\mathrm{c}}(\mathrm{MPa})$ & $\rho_{\mathrm{w}}(\%)$ & $\mathrm{P}_{\mathrm{cr}}(\mathrm{kN})$ & $\mathrm{P}_{\mathrm{d}}(\mathrm{kN})$ & $\mathrm{P}_{\mathrm{u}}(\mathrm{kN})$ & $\mathrm{P}_{\mathrm{u}} / \mathrm{P}_{\mathrm{d}}$ \\
\hline NSC-S0 & 32 & 0 & 13.52 & 45.08 & 47.54 & 1.05 \\
& & & 11.70 & 41.05 & 45.97 & 1.12 \\
& & & 9.20 & 33 & 47.36 & 1.43 \\
NSC-S1 & \multirow{2}{*}{32} & \multirow{2}{*}{0.56} & $\mathrm{NT}^{*}$ & $\mathrm{NT}$ & 49.68 & $\mathrm{NT}$ \\
& & & 18.52 & 43.30 & 72.18 & 1.67 \\
& & & 13.47 & 43.83 & 73.92 & 1.69 \\
& & & $\mathrm{NT}$ & $\mathrm{NT}$ & 73.87 & $\mathrm{NT}$ \\
HSC-S0 & \multirow{2}{*}{05} & & 16.93 & 37.81 & 60.31 & 1.59 \\
& & & 16.08 & 49.77 & 62.93 & 1.26 \\
& & & 21.65 & $\mathrm{NT}$ & 55.22 & $\mathrm{NT}$ \\
HSC-S1 & \multirow{2}{*}{65} & \multirow{2}{*}{0.56} & $\mathrm{NT}$ & $\mathrm{NT}$ & 55.90 & $\mathrm{NT}$ \\
& & & 17.56 & 63.70 & 83.90 & 1.32 \\
& & & 11.94 & 57.54 & 86.65 & 1.50 \\
& & & $\mathrm{NT}$ & $\mathrm{NT}$ & 88.00 & $\mathrm{NT}$ \\
& & & & 82.00 & $\mathrm{NT}$ \\
\hline
\end{tabular}

*NT : Not tested by Gom-Aramis

The diagonal cracking load represents approximately $70 \%$ of the ultimate load for beams without transverse reinforcement for both types of concretes. For higher values of this load, the concrete in the beam deteriorates along the diagonal cracks up to the diagonal fracture. In the beams with transverse 
reinforcement, this load represents roughly $65 \%$ of the ultimate load, and the concrete remains serviceable after installation of the transverse reinforcement, which restrains the evolution of diagonal cracks, up to changing the mode of failure to compression. In general, the presence of the transverse reinforcement slows the apparition of diagonal cracks for both types of concrete studied, and improves the resistance reserve of the beams, represented by the ratio $\mathrm{P}_{\mathrm{u}} / \mathrm{P}_{\mathrm{d}}$.

An increase in ultimate load was recorded for beams with transverse reinforcement compared to those without transverse reinforcement. This improvement, which varies up to $50 \%$ for the two types of concrete as indicated by the ratios $\mathrm{P}_{\mathrm{u}-\mathrm{S} /} / \mathrm{P}_{\mathrm{u}-\mathrm{S} 0}$ in Table 4 , is identical for the two materials. Comparable results have been reported in the literature on beams made with different compressive strengths of concrete, ranging between 20 and $68 \mathrm{MPa}[1,4,30,31]$. This shows that the effect of transverse reinforcement is practically the same for any type of concrete, though that effect is more pronounced with higher strength concrete, due to the better adhesion with the steel elements.

As regards the influence of the type of concrete, the ultimate load of beams made with HSC is greater than that of the beams made with NSC, because of the greater resistance of HSC, inducing better shear behaviour and also bending behaviour in HSC. It should be noted, however, that despite the large increase in compressive strength from 32 to $65 \mathrm{MPa}$, the loading capacity of the HSC beams has only increased from 15 to $22 \%$ compared to those in NSC, which shows that different HSCs have different shear strengths compared to NSC, or at least, there is a difference in the contribution of internal parameters of shear strength in the two materials. One of the major differences observed is in the aggregate interlocking contribution, which is reduced by the effect of trans-granular cracking observed in the HSC beams.

\subsection{Diagonal crack widths}

Fig. 6 shows the variation of the diagonal crack width measured by Gom-Aramis software, versus the transverse applied load.

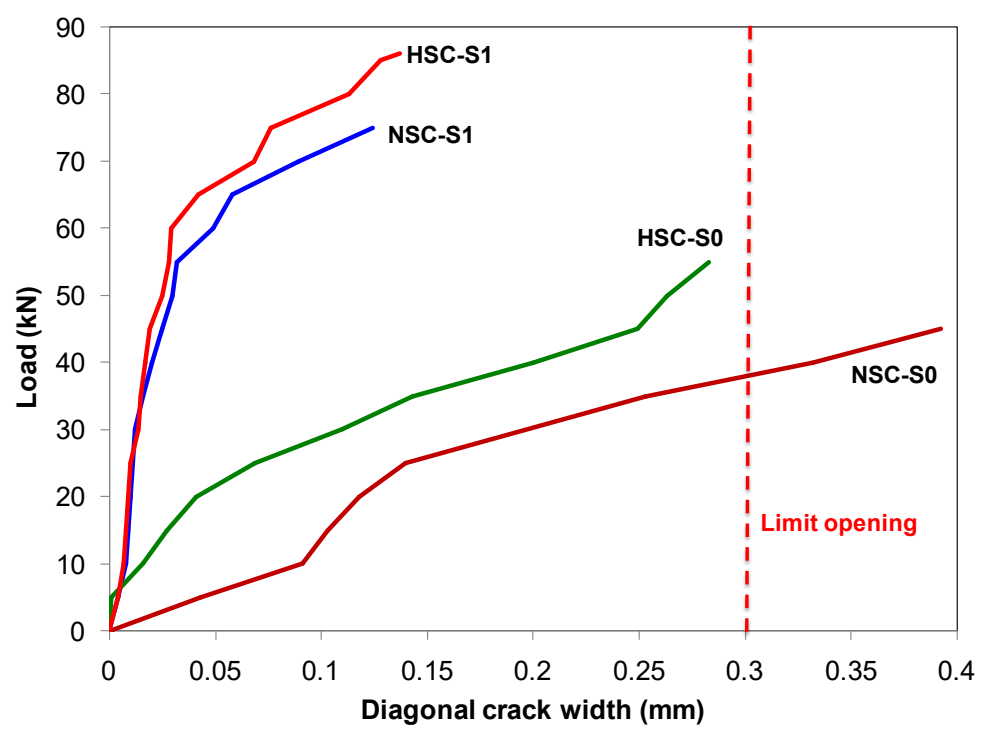

Fig. 6. Variation of diagonal crack widths of the tested beams. 
At high load level (greater than $70 \%$ of the ultimate load), the diagonal crack widths in the HSC-S1 beams are smaller than those in the NSC-S1 beams; the average ratio between the two widths is about 0.6. This is due to better adhesion with the steel and the high strength of RC beams, where the diagonal cracks are efficiently restrained and their width never exceeds $0.3 \mathrm{~mm}$, which is within the serviceability limit of cracking, up to the point of failure, which proves that this concrete performs well when properly reinforced. In all loading stages, as illustrated in Figs. 6 and 7, for the two types of concrete, the beams with transverse reinforcement have narrower diagonal cracks compared to those of beams without transverse reinforcement. This clearly demonstrates the need for transverse reinforcement in the shear zones in order to limit the crack widths in serviceable state.
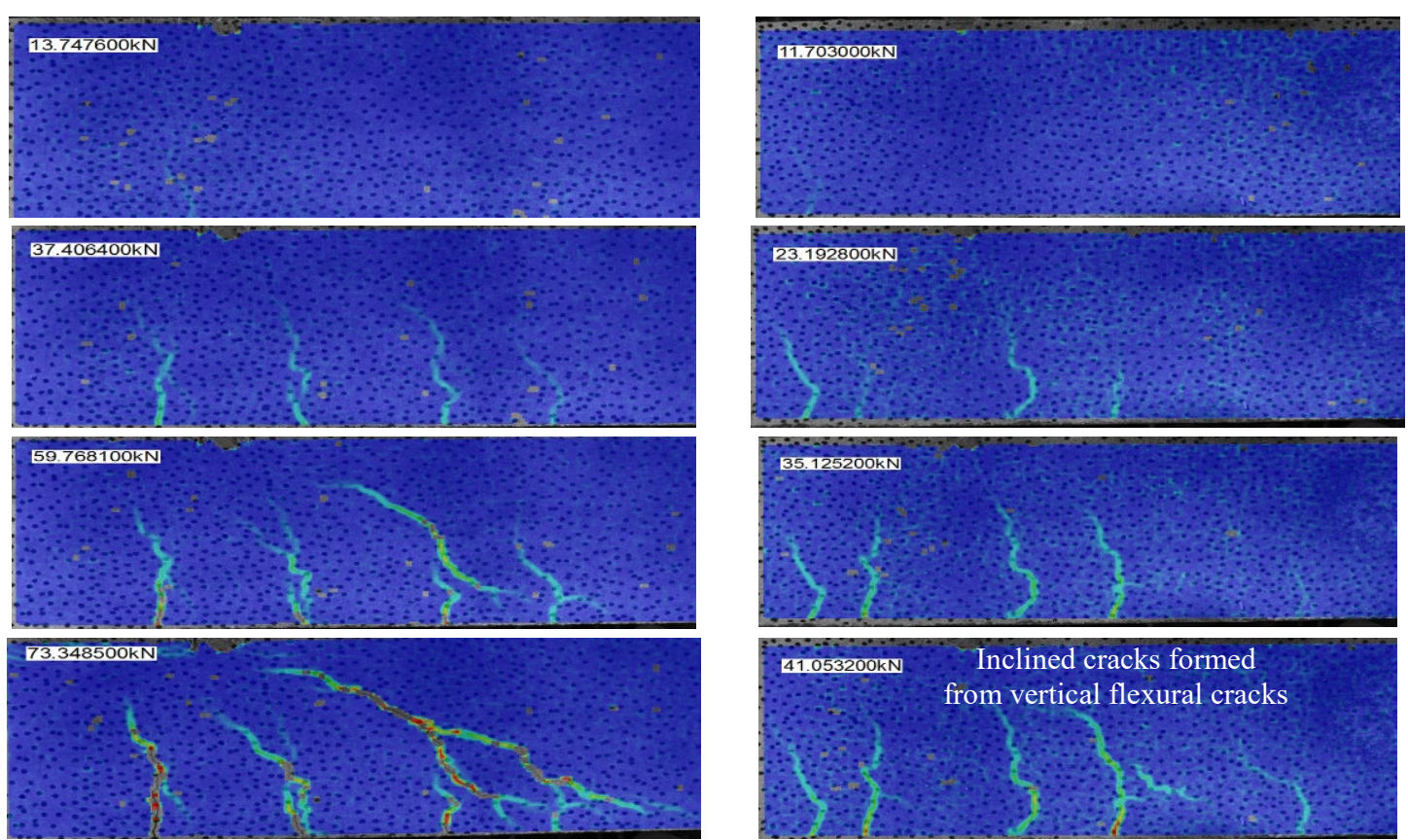

With transverse reinforcement

Without transverse reinforcement

(a) NSC beams
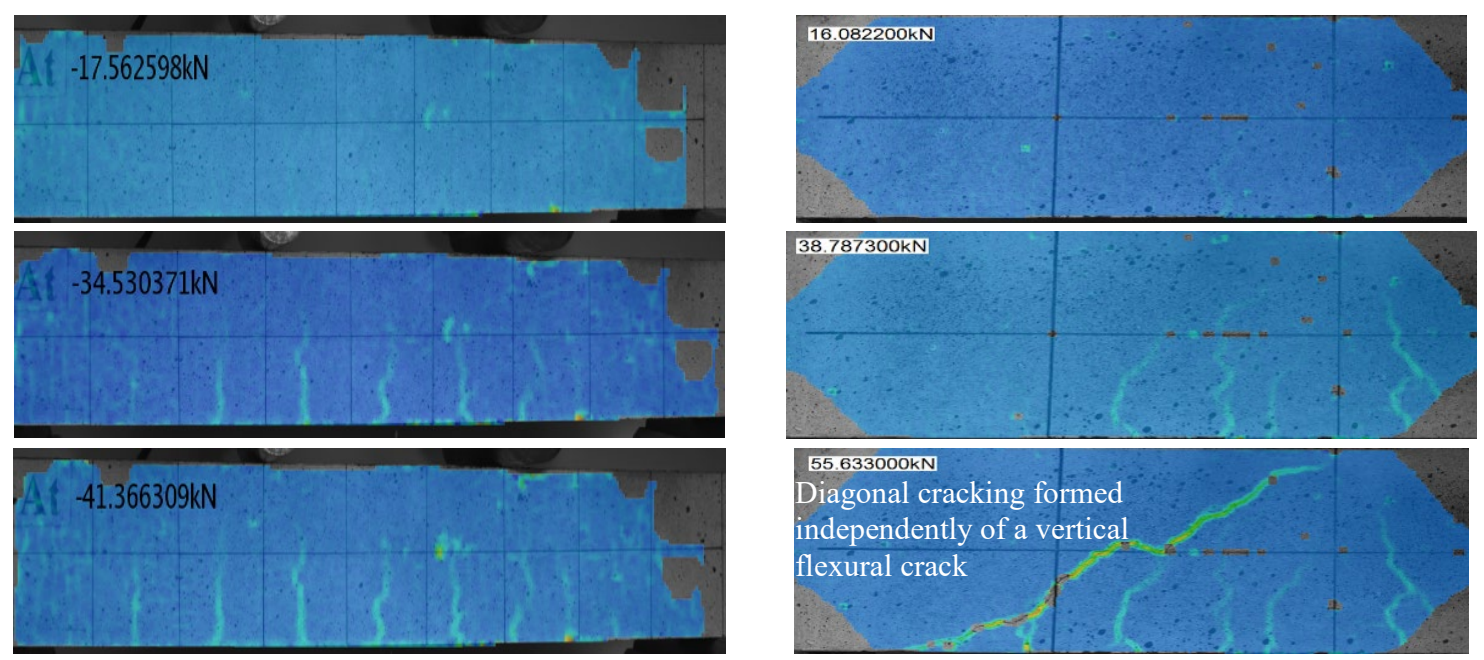


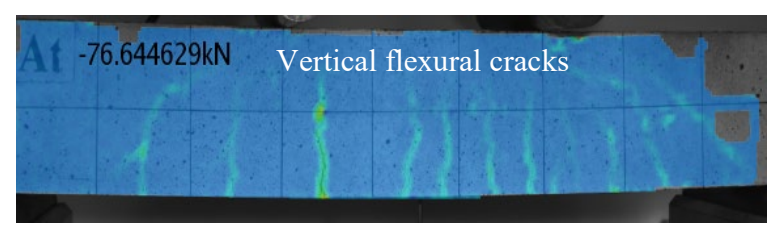

With transverse reinforcement

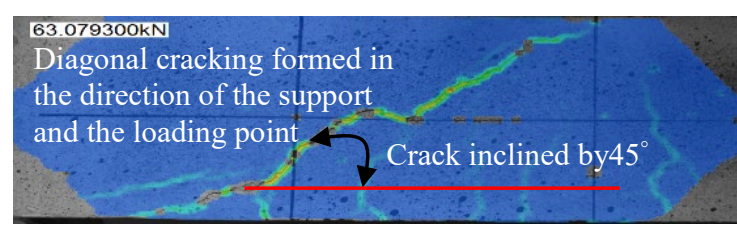

Without transverse reinforcement

(b) HSC beams

Fig. 7. Sequence of crack development within a shear zone in the tested beams.

(Photos obtained by Gom-Aramis)

\subsection{Load-deflection curves}

The effect of the transverse reinforcement is illustrated in Fig. 8, where the load-deflection curves for NSC and HSC beams are displayed. For beams without transverse reinforcement, the loaddeflection curves show two main phases:

- The first linear phase (phase OA) corresponds to the elastic behaviour before the appearance of cracking in the tension zone of concrete. In this phase, the beams remain stable with constant flexural stiffness.

- The second linear phase (phase $\mathrm{AB}$ ) corresponds to the formation of the first flexural crack in the tension zone of the beam, which consequently reduces the rigidity and the slope of the curve. The first crack occurs at a load of $\mathrm{P}_{\mathrm{cr}}=11.70 \mathrm{kN}$ for the NSC beams, and $\mathrm{P}_{\mathrm{cr}}=16.93 \mathrm{kN}$ for the HSC beams. This means that the increased compressive strength of HSC delays the manifestation of the first cracks.

However, while the compressive strength of concrete has doubled, the improvement in the flexural strength is only about $45 \%$ on its initial value. This result proves that the improvement of the performance of concrete in tension progresses in direct proportion to the compression force. The failure of the beam eventually occurs at the end of this second phase with very little plasticisation of the longitudinal reinforcement.

For beams with transverse reinforcement, the load-deflection curves are identical to those of beams without transverse reinforcement. In addition, before the failure corresponding to the plasticisation of the longitudinal reinforcement, a third, plastic phase (phase BC) occurs, as shown in Fig. 8.This plastic phase reflects the ductile behaviour of the beams with transverse reinforcement. Therefore, in addition to improving the shear behaviour, the presence of the transverse reinforcement increases the ductility of the RC elements in particular for those made of $\mathrm{HSC}$, which is initially considered as a brittle material. 


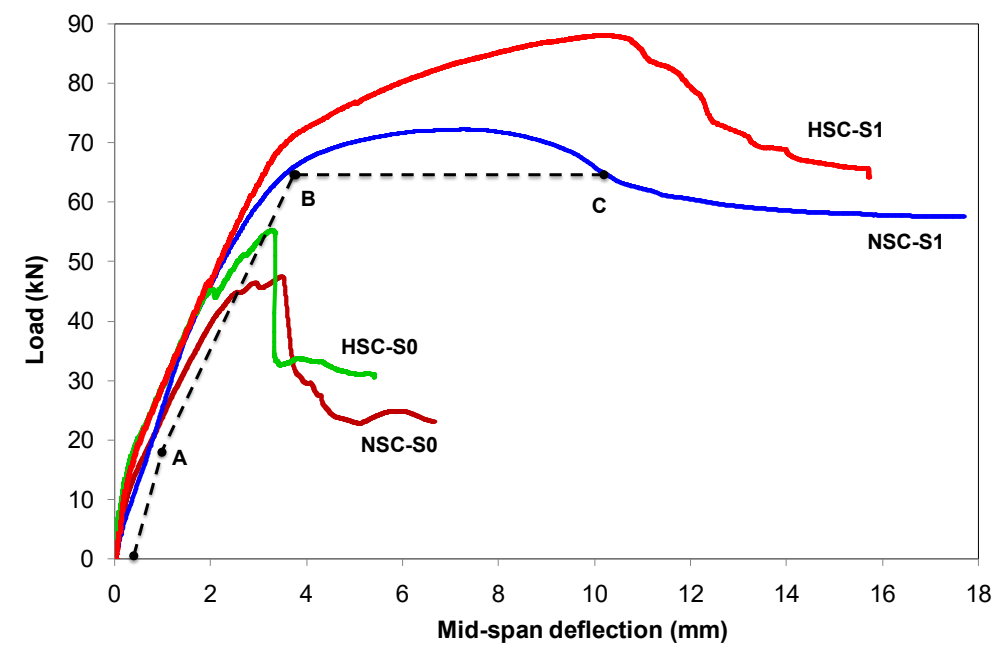

Fig. 8. Load-deflection curves for different tested beams.

This improvement of ductility is due to the better quality of the concrete-steel adhesion, ensuring a more efficient transmission of forces between the two materials and limiting any relative slippage between them.

Table 4 below, presents the ultimate deflections $\left(\Delta_{\mathrm{u}}\right)$ corresponding to the ultimate loads $\left(\mathrm{P}_{\mathrm{u}}\right)$, and the ratio $\left(\mathrm{P}_{\mathrm{u}-\mathrm{S} 1} / \mathrm{P}_{\mathrm{u}-\mathrm{S} 0}\right)$ and $\left(\Delta_{\mathrm{u}-\mathrm{S} 1} / \Delta_{\mathrm{u}-\mathrm{S} 0}\right)$ of the beams with and without transverse reinforcement, respectively.

Table 4 also shows that the ratio $\left(\Delta_{\mathrm{u}-\mathrm{S} 1} / \Delta_{\mathrm{u}-\mathrm{S} 0}\right)$ increases with increasing compressive strength, expressing a better deformability of the HSC beams in the presence of the transverse reinforcement and consequently substantially more ductile behaviour compared to NSC with transverse reinforcement. Therefore, it can be said that the presence of transverse reinforcement has an even more favourable effect on the ductility of HSC beams.

Table 4. Ultimate load and ultimate deflection of all tested beams.

\begin{tabular}{llllllll}
\hline Beams & $\begin{array}{l}\mathrm{P}_{\mathrm{u}-\mathrm{S} 1} \\
(\mathrm{kN})\end{array}$ & $\begin{array}{l}\mathrm{P}_{\mathrm{u}-\mathrm{S} 0} \\
(\mathrm{kN})\end{array}$ & $\mathrm{P}_{\mathrm{u}-\mathrm{S} 1} / \mathrm{P}_{\mathrm{u}-\mathrm{S} 0}$ & $\begin{array}{l}\Delta_{\mathrm{u}-\mathrm{S} 1} \\
(\mathrm{~mm})\end{array}$ & $\begin{array}{l}\Delta_{\mathrm{u}-\mathrm{S} 0} \\
(\mathrm{~mm})\end{array}$ & $\Delta_{\mathrm{u}-\mathrm{S} 1} / \Delta_{\mathrm{u}-\mathrm{S} 0}$ & $\begin{array}{l}\text { Number and type of crack } \\
(\text { along the study zone) }\end{array}$ \\
\hline NSC-S0-01 & -- & 47.54 & -- & -- & 3.47 & -- & $2 \mathrm{~F}+3 \mathrm{~F}-\mathrm{S}+1 \mathrm{D}$ \\
NSC-S0-02 & -- & 45.97 & -- & -- & 2.52 & -- & $2 \mathrm{D}$ \\
NSC-S0-03 & -- & 47.36 & -- & -- & 2.34 & -- & $2 \mathrm{~F}+1 \mathrm{~F}-\mathrm{S}+1 \mathrm{D}$ \\
NSC-S0-04 & -- & 49.68 & -- & -- & 3.21 & -- & - \\
NSC-S1-01 & 72.18 & -- & 1.52 & 7.23 & -- & 2.08 & - \\
NSC-S1-02 & 73.92 & -- & 1.61 & 7.92 & -- & 3.14 & $2 \mathrm{~F}+2 \mathrm{~F}-\mathrm{S}+2 \mathrm{D}$ \\
NSC-S1-03 & 74.89 & -- & 1.58 & 7.45 & -- & 3.18 & $5 \mathrm{~F}$ \\
NSC-S1-04 & 73.87 & -- & 1.49 & 8.08 & -- & 2.52 & - \\
HSC-S0-01 & -- & 60.31 & -- & -- & 2.75 & -- & $3 \mathrm{~F}-\mathrm{S}$ \\
HSC-S0-02 & -- & 62.93 & -- & -- & 4.56 & -- & $4 \mathrm{~F}+1 \mathrm{~F}-\mathrm{S}+2 \mathrm{D}$ \\
HSC-S0-03 & -- & 55.22 & -- & -- & 3.25 & -- & $2 \mathrm{D}$ \\
HSC-S0-04 & -- & 55.90 & -- & -- & 3.24 & - & - \\
HSC-S1-01 & 83.90 & -- & 1.39 & 10.97 & - & 3.99 & $6 \mathrm{~F}+1 \mathrm{~F}-\mathrm{S}$ \\
HSC-S1-02 & 86.65 & -- & 1.38 & 11.70 & - & 2.56 & $7 \mathrm{~F}+2 \mathrm{~F}-\mathrm{S}$ \\
HSC-S1-03 & 88.00 & -- & 1.59 & 10.30 & -- & 3.17 & $8 \mathrm{~F}+1 \mathrm{~F}-\mathrm{S}+2 \mathrm{D}$ \\
HSC-S1-04 & 82.00 & -- & 1.47 & 11.68 & -- & 3.60 & - \\
\hline F = Flexural crack & D = Diagonal crack & F-S $=$ Flexural-Shear crack
\end{tabular}




\subsection{Strain variation in the stirrups}

The development of strains in the transverse reinforcement indicates the contribution of concrete to the shear strength of RC beams. Fig. 9 shows the evolution of strains in the stirrups of both NSC and HSC beams. The strain in the stirrups in the area with higher shear force, where the first diagonal crack occurs, was delayed in HSC beams and in every case, comparatively less. The use of stirrups improves the shear strength and hence the ultimate load of HSC beams by comparison with NSC beams. It was noted during the testing process that before the appearance of the first diagonal crack, the behaviour of the stirrups is almost identical for both NSC and HSC beams, with negligible deformation. At the first diagonal crack load, an increase of $53 \%$ of strain in the stirrups of NSC beams is recorded, compared to those of HSC beams, which, once again, demonstrates the efficiency of HSC in RC beams.

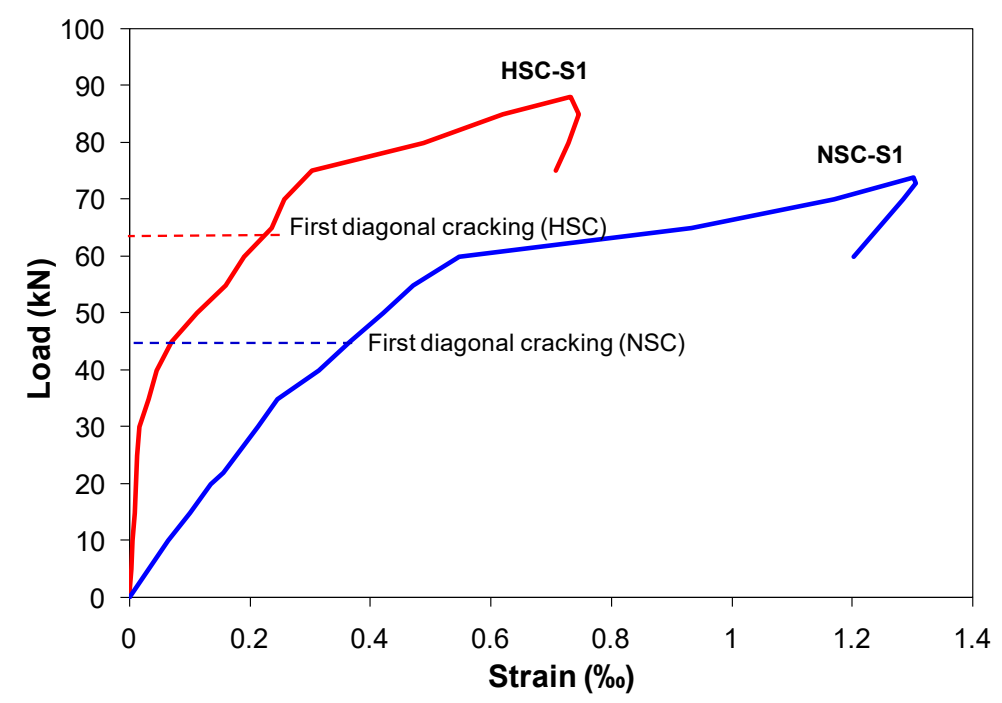

Fig. 9. Strain variation in stirrups of NSC and HSC beams.

\subsection{Strain evolution in the longitudinal reinforcement}

Fig. 10 shows the evolution of strain in the longitudinal reinforcement depending on the loading applied, for NSC and HSC beams. Before the appearance of the first flexural crack, the behaviour of the longitudinal reinforcement is alike for the two types of tested beams, with strain equal to zero for both NSC and HSC beams. This shows that, before cracking, the concrete is able to withstand the whole of the applied load. After cracking, the strain in the longitudinal reinforcement increases in a linear manner with the load, and the cracking load is higher for HSC beams, which is attributable to good adhesion with the steel reinforcement, resulting in good transmission of loads between the concrete and the reinforcement steel, showing significant ductility. The post-elastic behaviour of beams began to manifest at an approximate strain of $2.5 \%$, and the ultimate deformation of $10 \%$, recommended by the various international design codes for the longitudinal reinforcement in designing RC structures, is exceeded in both NSC and HSC beams. 


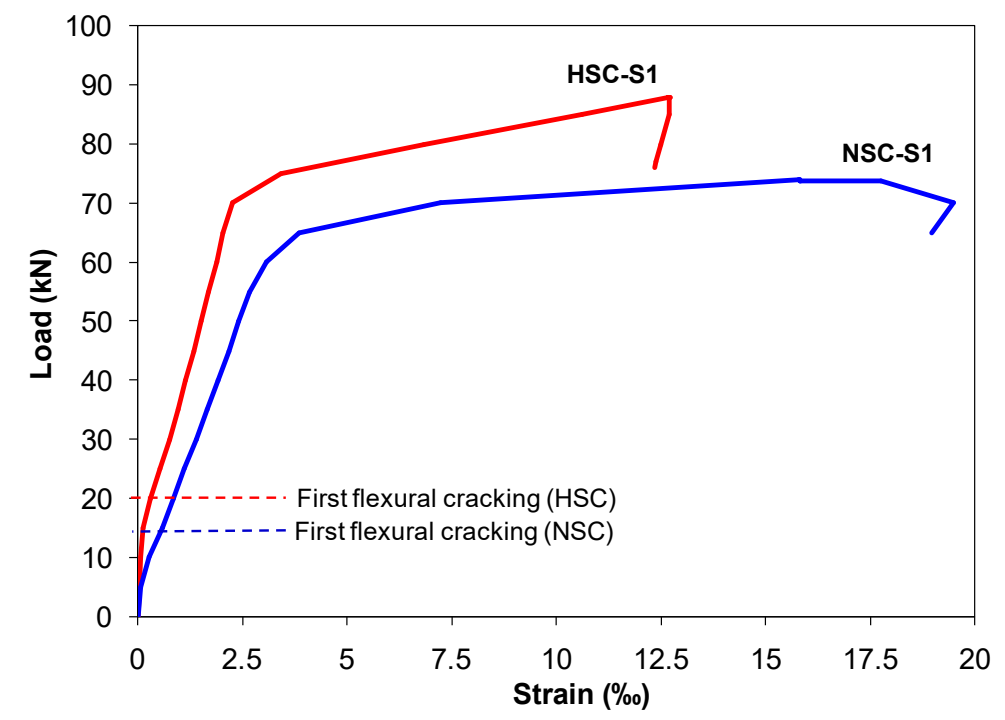

Fig. 10. Strain variation in the longitudinal reinforcement of NSC and HSC beams.

\subsection{Strain variation in the compressed concrete}

The recorded images show the strains in the most compressed fibre in the cross-sectional area of the beams obtained versus the applied load. Fig. 11 shows the evolution of the strains in the most compressed fibre of concrete located between the two loading points. In this zone, the crushing of concrete observed after flexural cracking is sufficiently wide and long. This shifts the neutral axis to the top of the concrete section, and hence significantly reduces the area of compressed concrete. This crushing of the concrete in the compressed zone of the beam has been observed especially in the presence of transverse reinforcement in beams, which prevented the shear failure of RC beams, as clearly shown in Figs. 5(a) and (c). In particular, in the HSC beams, the ultimate deformation of 3.5\%, recognised by the different international design codes, is exceeded before failure occurs. This ultimate deformation is equal to $4.5 \%$, which shows that high strength RC beams have good ductility.

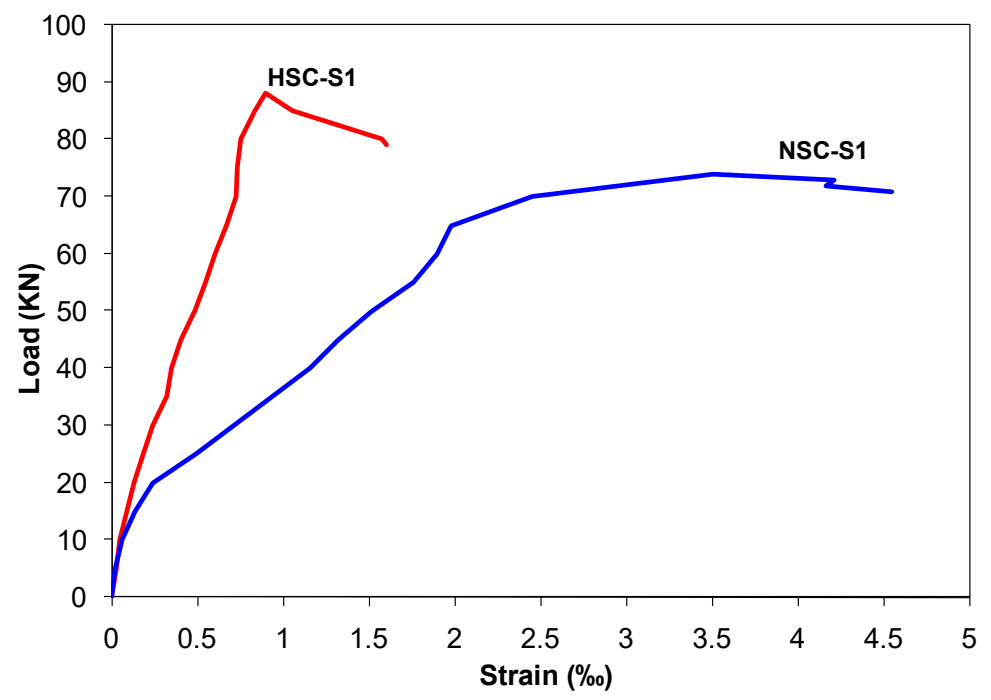

Fig. 11. Strain variation in compressed concrete in NSC and HSC beams. 


\subsection{Comparison of experimental results to the theoretical values}

This section compares the ultimate shear strength $\left(v_{\mathrm{u}}=\mathrm{V}_{\mathrm{u}} / \mathrm{bd}\right)$ obtained by the present experimental investigation and the theoretical values predicted by different expressions in the literature. In particular, for the beams without transverse reinforcement, the expressions suggested by Zsutty [32] (Eq. (1)), Bažant and Kim [33] (Eq. (2)), and Hamrat et al. (Eq. (3)) [4] are used to estimate the contribution of concrete $v_{c}$, expressed in $\mathrm{MPa}$, to the ultimate shear strength:

$$
\begin{aligned}
& v_{c}=\left(160 \rho_{s} f_{c}\right)^{\frac{1}{3}}\left(\frac{d}{a}\right)^{\frac{4}{3}} \quad \text { for } \frac{a}{d}<2.5 \\
& v_{c}=0.83\left(\frac{1}{\sqrt{1+d /\left(25 d_{a}\right)}}\right)\left(\rho_{s}\right)^{1 / 3}\left(\sqrt{f_{c}}+250 \sqrt{\frac{\rho_{s}}{(a / d)^{5}}}\right) \\
& v_{c}=3.88\left(f_{c} \rho_{s} \frac{d}{a}\right)^{0.47} \quad \text { for } \frac{a}{d}<2.5
\end{aligned}
$$

When transverse reinforcement is present in the beam, the expression (Eq. (4)) from Russo and Puleri [34] is used to estimate the contribution of stirrups $v_{s}$, in MPa, to the ultimate shear strength:

$$
v_{\mathrm{s}}=\frac{1.67 \sqrt{\mathrm{f}_{\mathrm{c}}}}{\sqrt{\mathrm{f}_{\mathrm{c}}}+250 \sqrt{\frac{\rho_{\mathrm{s}}}{(\mathrm{a} / \mathrm{d})^{5}}}} \rho_{\mathrm{w}} \mathrm{f}_{\mathrm{yw}}
$$

where $f_{c}$ is the concrete cylinder compressive strength (MPa), $\rho_{\mathrm{s}}=\mathrm{A}_{\mathrm{s}} / \mathrm{b}_{\mathrm{w}} \mathrm{d}$ is the ratio of the tension steel longitudinal reinforcement, $d$ is the effective depth of the beam $(\mathrm{mm})$, a is the shear span of the beam $(\mathrm{mm}), \mathrm{d}_{\mathrm{a}}$ is the maximum size of the aggregate $(\mathrm{mm}), \rho_{\mathrm{w}}=\mathrm{A}_{\mathrm{w}} / \mathrm{b}_{\mathrm{w}} \mathrm{s}$ is the ratio of the steel transverse reinforcement and $\mathrm{f}_{\mathrm{yw}}$ is the yield strength of the steel stirrups (MPa).

Fig. 12 illustrates the experimental results obtained in this research on ultimate shear strength for NSC and HSC beams. Generally speaking, the results show that the shear capacity of HSC beams is higher than NSC beams, which means that, in general, HSC can be considered a more reliable structural material. However, this increase in ultimate shear strength is limited, never exceeding $25 \%$. The improved compressive strength of HSC gives higher values. This result can be related to the internal parameters of ultimate shear force in HSC, which are higher than those in NSC, and also to the minimal effect of tension strength of NSC, which can be taken as similar to the shear effect. Both effects are dependent on the quality of the cement paste and adherence of the aggregates. With this in mind, the anti-crush capacity of HSC is greatly improved, while the shear effect is not, compared to NSC. 


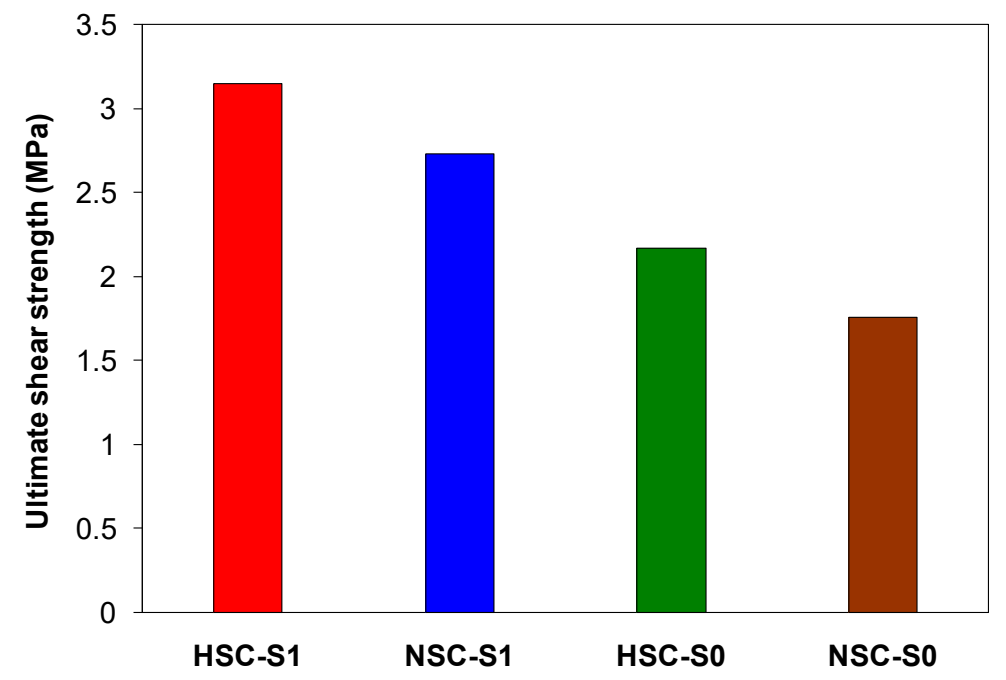

Fig. 12. Experimental values of ultimate shear strength.

The ultimate shear strength of NSC and HSC beams is dependent on the contribution of the concrete $v_{\mathrm{c}}$ and of the transverse reinforcement $v_{\mathrm{s}}$, if they are in place. The series of beams NSC-S0 and HSC-S0 are not reinforced transversally, so the ultimate shear strength of these beams is governed by the concrete $v_{\mathrm{c}}$. Tables 5 and 6 contain the results obtained by different expressions, which are presented in Figs. 13(a) and (b).

The concrete contribution $v_{\mathrm{c}}$ to the shear strength found in the experiment represents $65 \%$ of the total shear capacity, while the transverse reinforcement contribution $v_{\mathrm{s}}$ represents $35 \%$, for each type of concrete. The theoretical values obtained by the different expressions to predict the contribution of concrete to the shear strength of RC beams are quite close to one another. The difference in values between the theoretical prediction and the experimental results can be considered acceptable. However, the expression put forward by Hamrat et al. [4] (Eq. (3)), based on experimental work with HSC beams, yields a reasonably accurate prediction of concrete's contribution to the shear strength, with a ratio $v_{\mathrm{u}-\text { Test }} / v_{\mathrm{u}-\text {-Predicted }}$ of 1.06 and 0.93 for NSC and HSC beams, respectively.

Table 5. Experimental results on ultimate shear strength for beams without stirrups.

\begin{tabular}{llllllll}
\hline \multirow{2}{*}{ Beam } & $\begin{array}{l}v_{\mathrm{u}-\text { Test Average }} \\
\text { (MPa) }\end{array}$ & \multicolumn{2}{l}{$v_{\mathrm{u}-\text {-Predicted }}(\mathrm{MPa})$} & \multicolumn{4}{c}{$v_{\mathrm{u}-\text { Test }} / v_{\mathrm{u}-\text { Predicted }}$} \\
\cline { 3 - 8 } NSC-S0 & 1.76 & Eq.(1) & Eq.(2) & Eq.(3) & Eq.(1) & Eq.(2) & Eq.(3) \\
\cline { 3 - 8 } HSC-S0 & 2.17 & 1.34 & 1.49 & 1.66 & 1.31 & 1.18 & 1.06 \\
\hline
\end{tabular}


Table 6. Experimental results on ultimate shear strength for beams with stirrups.

\begin{tabular}{|c|c|c|c|c|c|c|c|}
\hline \multirow{2}{*}{ Beam } & \multirow{2}{*}{$\begin{array}{l}v_{\mathrm{u}-\text { Test Average }} \\
(\mathrm{MPa})\end{array}$} & \multicolumn{3}{|c|}{$v_{\mathrm{u}-\text { Predicted }}(\mathrm{MPa})$} & \multicolumn{3}{|c|}{$v_{\mathrm{u} \text {-Test }} / v_{\mathrm{u} \text {-Predicted }}$} \\
\hline & & Eq.(1)+(4) & Eq.(2)+(4) & Eq.(3)+(4) & Eq.(1)+(4) & Eq.(2)+(4) & Eq.(3)+(4) \\
\hline NSC-S1 & 2.73 & 2.77 & 2.92 & 3.09 & 0.98 & 0.93 & 0.88 \\
\hline HSC-S1 & 3.15 & 3.33 & 3.51 & 3.96 & 0.94 & 0.90 & 0.79 \\
\hline
\end{tabular}

The contribution of the transverse reinforcement $v_{\mathrm{s}}$ to the improvement of the shear strength in series NSC-S1 and HSC-S1 beams can also be seen in Table 6 and in Figs 13(a) and (b). The transverse reinforcement started to exercise an influence as soon as the first diagonal cracks appeared [10,35]. Actually, the transverse reinforcement begins to resist certain shear stresses well before diagonal cracks become visible [36]. After the development of the diagonal crack, most of the shear force is resisted by the transverse reinforcement [37]. It can be seen that the expression given by Russo and Puleri [34] (Eq. (4)) significantly overestimates the contribution of transverse reinforcement to the shear strength of NSC-S1 and HSC-S1 beams; the average overestimation is about $47 \%$ and $66 \%$, respectively. However, the overestimation of the contribution of transverse reinforcement to the shear strength of HSC beams [2] has also been recorded by the models in the four codes namely: ACI 318 [38], BS 8110 [39], Eurocode 2 [40], and NZS 3101 [41]. This may be due to the fact that the transverse reinforcement's contribution to the shear strength adopted in Eq. (4) and in the four code models is based on the condition under which such reinforcement yields.

In the present experimental work, when the transverse reinforcement was used, failure by crushing of concrete in the compression zone, close to the top of a diagonal crack (Fig. 5(c)), is observed in the tested beams. This mode of failure is not considered by the Richter [42] and Mörsh [43] truss analogy and consequently not considered in these models. Hence, more refinement is needed in these models to reflect the real contributions of concrete and transverse reinforcement to the shear strength of RC beams.

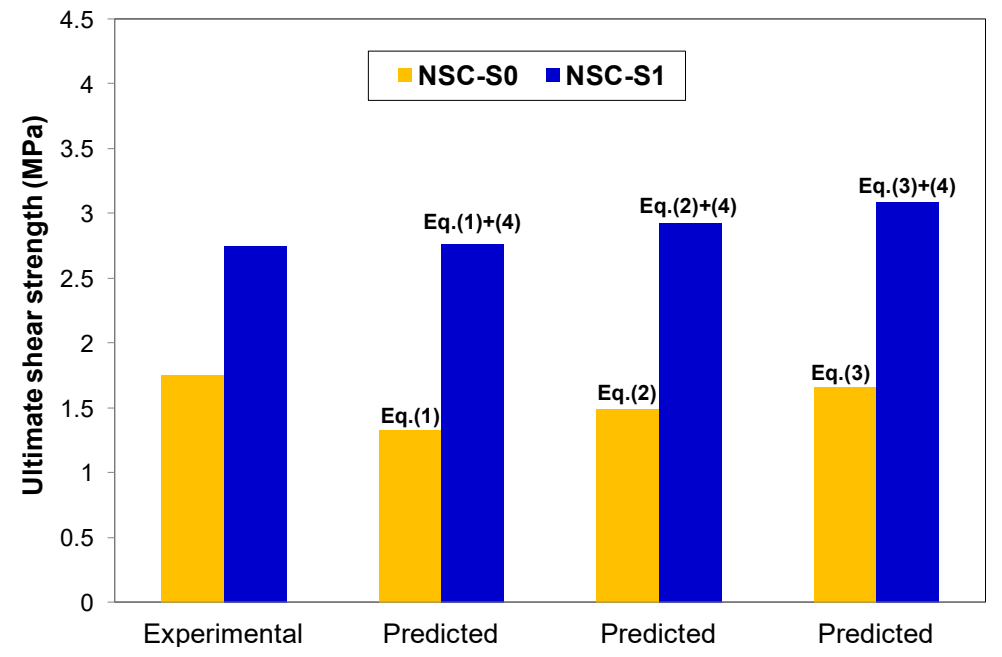

(a) NSC beams 


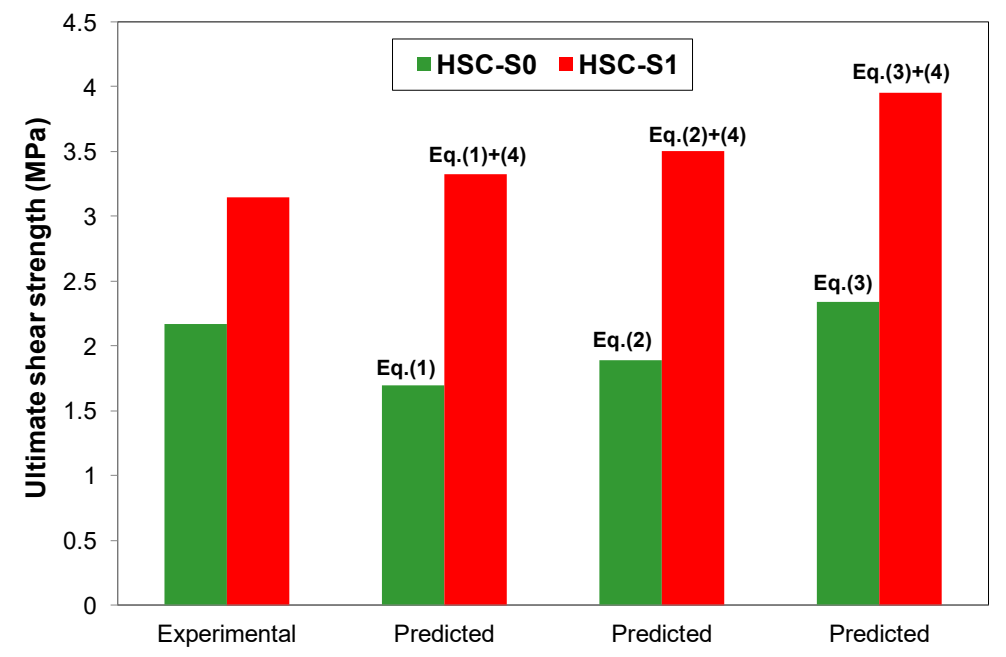

(b) HSC beams

Fig. 13. Comparison of the experimental and theoretical ultimate shear strength.

\section{Finite element model development}

3D NLFEA was used to predict the shear behaviour of simply supported RC beams in a fourpoint bending test. The FE simulation ANSYS $^{\odot}$ software [44] was used to model the shear behaviour of the RC beams. The nonlinear models were validated by comparing the predicted load-deflection response, ultimate load, cracking load, ultimate deflection and maximum diagonal crack widths with the experimental results.

\subsection{Description of elements}

Multiple element types were used to model the RC beams. The concrete was modelled using the element SOLID65 (Fig. 14(a)). SOLID185 was used to model the loading and supporting steel plates (Fig. 14(b)). The longitudinal and transverse reinforcement were modelled with a two-node spar element, LINK180, as shown in Fig. 15(c) [44-49].

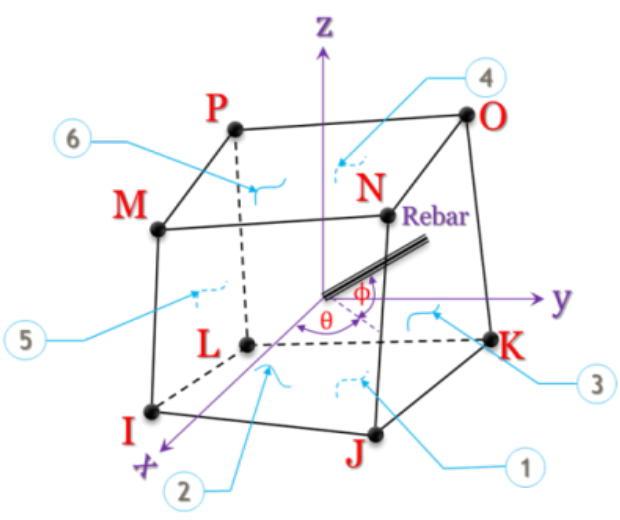

(a) SOLID65

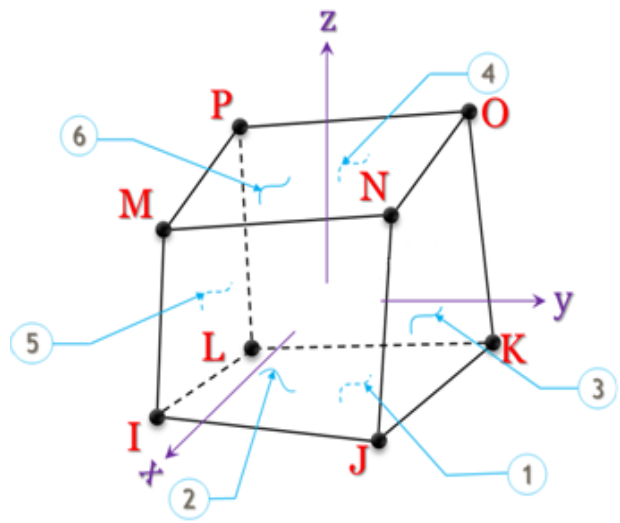

(b) SOLID185 


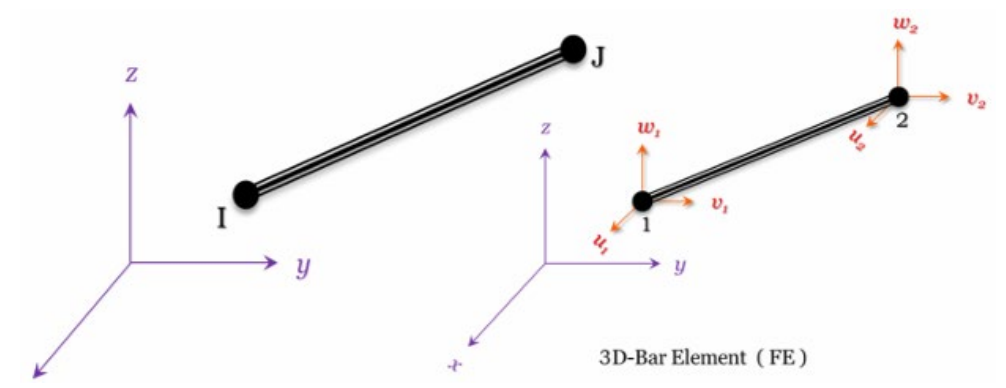

(c) LINK180

Fig. 14. Details of the types of finite element used [44-49].

\subsection{Material properties and real constants}

Concrete has different compressive and tensile behaviour and exhibits quasi-brittle properties. The various material parameters which are input in the NLFEA ANSYS ${ }^{\odot}$ program, to simulate the nonlinear behaviour of concrete, include isotropic material properties for concrete such as Poisson's ratio, elastic modulus, multi-linear stress-strain values and other concrete parameters such as compressive and tensile strength and shear coefficients. From the stress-strain relationship for concrete under uniaxial compression, the linear phase represents the elastic linear region. After, the plastic region (nonlinear region) starts subsequently. Therefore, the ultimate load cannot be achieved only by the elastic characteristics of the RC beam. The stress-strain constitutive relationship has to be defined for the plastic region. The FE model should be capable to predict the concrete failure by both cracking and crushing failure modes. In FE simulation $\operatorname{ANSYS}^{\odot}$ software, the multi-linear uniaxial compressive stress-strain curve for isotropic concrete is obtained by the following expressions [22]:

$\mathrm{f}=\frac{\mathrm{E}_{\mathrm{c}} \varepsilon}{1+\left(\frac{\varepsilon}{\varepsilon_{0}}\right)^{2}}$

$\varepsilon_{0}=\frac{2 \mathrm{f}_{\mathrm{c}}}{\mathrm{E}_{\mathrm{c}}}$

$\mathrm{E}_{\mathrm{c}}=\frac{\mathrm{f}}{\varepsilon}$

where, $\mathrm{f}$ is the stress (MPa) at strain $\varepsilon, \mathrm{f}_{\mathrm{c}}$ is the compressive strength (MPa) corresponding to the strain $\varepsilon_{0}$ and $\mathrm{E}_{\mathrm{c}}$ is the elastic modulus of concrete $(\mathrm{MPa})$.

The detailed material properties of NSC and HSC used in the numerical model and implemented in ANSYS $^{\odot}$ are given in Table 7. Table 8 presents the material properties of the steel reinforcement.

Table 7. Material properties of concrete.

\begin{tabular}{llllll}
\hline Material model number & Element type & Material properties & & NSC & HSC \\
\hline 1 & SOLID65 & Elastic modulus $(\mathrm{GPa})$ & & 38.7 & 42.3 \\
& & Poisson's ratio & Transfer & 0.2 & 0.2 \\
& & Open shear & coefficient & 0.9 & 0.5 \\
& & Closed shear & 0.9 \\
& & Uniaxial cracking $\left(\mathrm{f}_{\mathrm{t}}\right)$ & Stress $(\mathrm{MPa})$ & 3.2 & 5.9 \\
& & Uniaxial crushing $\left(\mathrm{f}_{\mathrm{c}}\right.$ ) & Stris & 65 \\
\hline
\end{tabular}


Table 8. Material properties of steel reinforcement.

\begin{tabular}{llll}
\hline Material model number & Element type & Material properties & \\
\hline 2 & LINK180 & Elastic modulus & $204000 \mathrm{MPa}$ \\
& & Poisson's ratio & 0.3 \\
& & Yield stress (Elastic limit) & $500 \mathrm{MPa}$ \\
\hline
\end{tabular}

The SOLID185 element requires elastic linear isotropic material. Table 9 presents the material properties of the loading and supporting steel plates.

Table 9. Material properties of steel plates.

\begin{tabular}{llll}
\hline Material Model Number & Element Type & Material Properties & \\
\hline 3 & SOLID185 & Elastic modulus & $200000 \mathrm{MPa}$ \\
& & Poisson's ratio & 0.3 \\
\hline
\end{tabular}

Furthermore, the real constants for SOLID65 and LINK180 element types are shown in Tables 10 and 11, respectively. A value of zero is required for all real constants for SOLID65 element, because the concrete used in this study is non-fibrous.

Table10. Real constants for SOLID65.

\begin{tabular}{lll|l}
\hline Real constant set & Element type & Real constants & Real constants for Rebar \\
\hline 1 & SOLID65 & Material number & 0 \\
& & Volume ratio & 0 \\
& & Orientation angle $(\theta)$ & 0 \\
& & Orientation angle $(\varphi)$ & 0 \\
\hline
\end{tabular}

Table11. Real constants for LINK180.

\begin{tabular}{lll}
\hline Real constant set & LINK180 element type & $\begin{array}{l}\text { Real constants } \\
\left(\text { sectional area }\left(\mathrm{mm}^{2}\right)\right)\end{array}$ \\
\hline 2 & Tensile longitudinal reinforcement & 78.5 \\
& Compressive longitudinal reinforcement & 50.24 \\
& Transverse reinforcement & 28.26 \\
\hline
\end{tabular}

\subsection{Finite element simulation}

The FE model of each RC beam generated in NLFEA ANSYS ${ }^{\circ}$ with boundary condition and loading position is shown in Fig. 15(a). The perfect bond between the steel reinforcement and the concrete is considered. For this purpose, the steel reinforcement within the concrete was modelled using the discrete method (Fig. 15(b) and Fig. 15(c)). The SOLID65 element was connected to the adjacent nodes of the LINK180 element, so the two materials could share the same nodes.

The contact between the loading plates and the RC beam was generated using CONTA174 and TARGE170 element. CONTA174 is an 8-node element that is intended for general flexible-flexible and rigid-flexible contact analysis, is associated with the 3D target segment elements (TARGE170) using a shared real constant set number. Contact pairs were generated between the RC beam surface 
and the loading steel plates to transfer the load and reduce the local stress concentration at the loading point. In this study, a surface-to surface contact was created considering the loading plates as rigid.

Also, the contact between the RC beam surface and the supporting steel plates was created using the friction coefficient of 0.05 ; normal penalty stiffness and penetration tolerance were of 1.0 and 0.0001 , respectively.

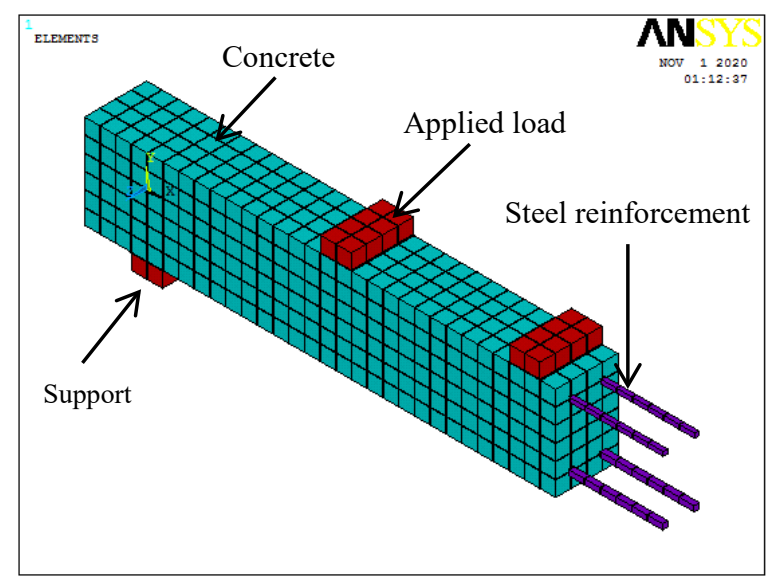

(a)

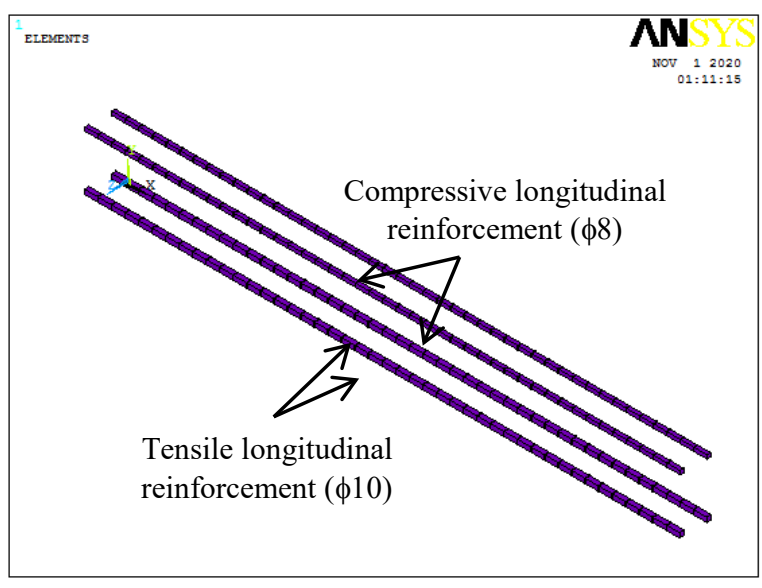

(b)

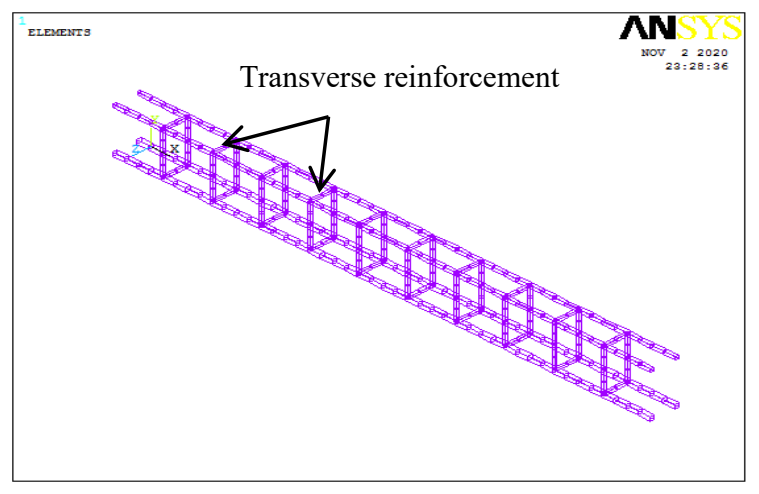

(c)

Fig. 15. Finite element model of RC beam: (a) numerical model; (b) modelling of longitudinal reinforcement without stirrups (c) modelling of longitudinal reinforcement with stirrups.

Convergence and accuracy of numerical results is sensitivity with the mesh size. In order to find the optimum mesh size, three trial analyses were performed using mesh sizes 20,30 and $40 \mathrm{~mm}$. Table 12 shows the influence of mesh size on the ultimate mid-span deflection of NSC-S1 beam. The value of ultimate mid-span deflection corresponding to the mesh size of $20 \mathrm{~mm}$ is approximately equal to the experimental value of $6.18 \mathrm{~mm}$. Hence, an optimum mesh size of $20 \mathrm{~mm}$ was adopted for the present numerical study. Moreover, the mesh size of $20 \mathrm{~mm}$ reduced computational time and computer disk space requirements significantly than that of smaller mesh size. The finite element model of RC beams was approximately composed of 1635 nodes and 1348 elements. 
Table 12. Influence of mesh size on ultimate mid-span deflection of NSC-S1 beam.

\begin{tabular}{lccc}
\hline $\begin{array}{c}\text { Mesh sizes } \\
(\mathrm{mm})\end{array}$ & Experimental & Numerical & (Experimental-Numerical)/Experimental \\
\cline { 2 - 4 } & $\Delta_{\mathrm{u}}(\mathrm{mm})$ & $\Delta_{\mathrm{u}}(\mathrm{mm})$ & $\Delta_{\mathrm{u}}$ \\
\hline 20 & 6.18 & 7 & $-13.27 \%$ \\
30 & 6.18 & 8.56 & $-38.51 \%$ \\
40 & 6.18 & 9.78 & $-58.25 \%$ \\
\hline
\end{tabular}

In order to predict the nonlinear shear response of RC beams, the total load applied to a FE model was divided into a series of load steps (load increments). At the end of each incremental solution, the stiffness matrix of the model was adjusted to reflect nonlinear changes in structural stiffness before proceeding to the next load step. The NLFEA ANSYS ${ }^{\odot}$ software employs Newton-Raphson equilibrium iterations for updating the model stiffness. Newton-Raphson approach provides convergence at the completion of each load step within tolerance limits. Fig. 16 illustrates the use of the Newton-Raphson method in a single degree of freedom (DOF) nonlinear analysis. Before to each solution, the Newton-Raphson method evaluates the residual load vector, which is the difference between the applied load vector and the restoring force vector calculated from the element stresses. The algorithm then carries out a linear solution, using the residual load vector, and checks for convergence. If convergence criteria are not obtained, the residual load vector is re-evaluated and the stiffness matrix is corrected, hence a new solution is achieved. This iterative procedure continues until the problem converges $[22,44]$.

In the present study, convergence criteria were based on force and displacement, and the convergence tolerance limits were initially selected by the NLFEA software ANSYS ${ }^{\odot}$. It was found that solution convergence for the models was difficult to attain due to the nonlinear response of RC beams. Therefore, in order to obtain convergence of the solutions the convergence tolerance limits was increased to five times the default tolerance limits.

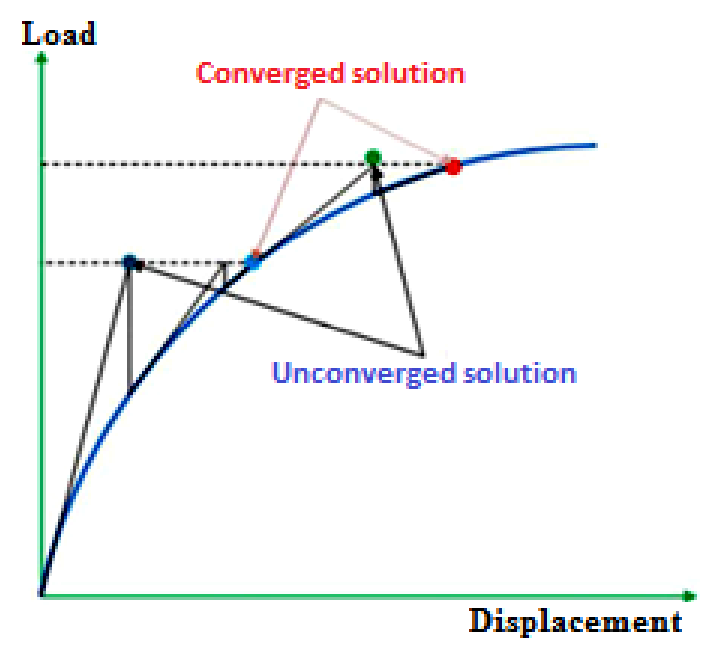

Fig. 16. Newton-Raphson method for single DOF [22, 44]. 


\subsection{Numerical simulation results and discussion}

\subsubsection{Numerical model validation}

NLFEA was conducted to simulate the shear behaviour of RC beams with and without transverse reinforcement, subjected to a four-point bending test. FE modelling of RC beams was validated by comparing the load-deflection curves produced by the numerical model with those illustrating the experimental data for NSC and HSC, as shown in Figs. 17(a) and (b), respectively. The deflection was measured at the mid-span of each beam. From these plotted results, it is clear that the FEA is generally in good agreement with the experimental tests at all stages of loading until failure. Generally, the numerical models are stiffer than the beams tested in the real world. This is due to the bond between the concrete and steel reinforcement. In the numerical model, the bond is assumed to be perfect, which could add stiffness during the nonlinear behaviour. Also, in the experimental test, dry shrinkage micro-cracks are present in the concrete to some extent.

Table 13 compares the ultimate load $\left(\mathrm{P}_{\mathrm{u}}\right)$, cracking load $\left(\mathrm{P}_{\mathrm{cr}}\right)$, ultimate deflection $\left(\Delta_{\mathrm{u}}\right)$ of the experimental beams and those from the FE models. The difference values between the numerical and experimental values range from -11.08 to $+0.61 \%$ for cracking load, and from -2.02 to $-0.52 \%$ for ultimate load. Also, these values for ultimate deflection at mid-span of beam vary between -13.27 and $-1.01 \%$. Consequently, it can be concluded that the numerical approach based on FEA is reliable and could be used as a valid numerical tool in investigating the shear behaviour of RC beams.

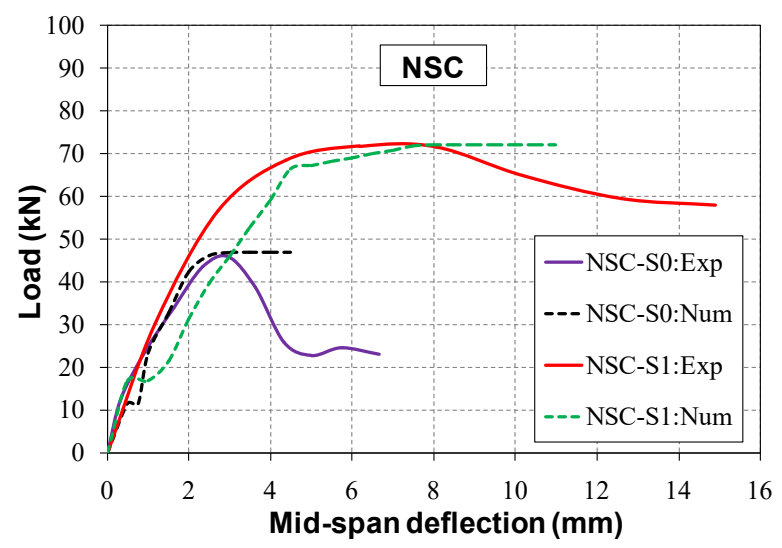

(a)

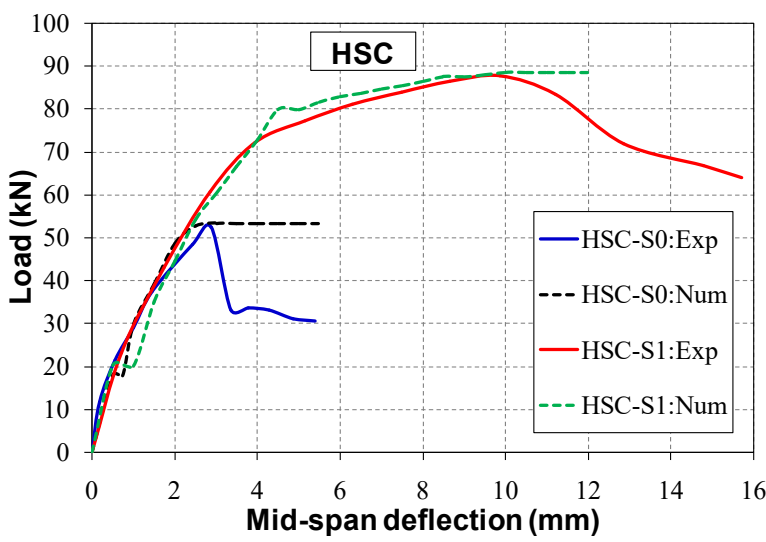

(b)

Fig. 17. Load-deflection responses obtained from FEA and measured experimental data (a) NSC (b) HSC.

Table 13. Numerical model validation.

\begin{tabular}{rlllllllll}
\hline \multirow{2}{*}{ Beams } & \multicolumn{3}{l}{ Experimental } & \multicolumn{3}{c}{ Numerical } & \multicolumn{3}{c}{ (Experimental-Numerical)/Experimental } \\
\cline { 2 - 9 } & $\mathrm{P}_{\mathrm{cr}}(\mathrm{kN})$ & $\mathrm{P}_{\mathrm{u}}(\mathrm{kN})$ & $\Delta_{\mathrm{u}}(\mathrm{mm})$ & $\mathrm{P}_{\mathrm{cr}}(\mathrm{kN})$ & $\mathrm{P}_{\mathrm{u}}(\mathrm{kN})$ & $\Delta_{\mathrm{u}}(\mathrm{mm})$ & $\mathrm{P}_{\mathrm{cr}}$ & $\mathrm{P}_{\mathrm{u}}$ & $\Delta_{\mathrm{u}}$ \\
\cline { 2 - 10 } NSC-S0 & 11.47 & 45.96 & 2.97 & 11.4 & 46.89 & 3 & $+0.61 \%$ & $-2.02 \%$ & $-1.01 \%$ \\
NSC-S1 & 15.17 & 71.77 & 6.18 & 16.8 & 72.14 & 7 & $-10.74 \%$ & $-0.52 \%$ & $-13.27 \%$ \\
HSC-S0 & 16.16 & 52.45 & 2.87 & 17.95 & 53.39 & 3 & $-11.08 \%$ & $-1.79 \%$ & $-4.53 \%$ \\
HSC-S1 & 18.22 & 87.79 & 9.85 & 20.21 & 88.66 & 10 & $-10.92 \%$ & $-0.99 \%$ & $-1.52 \%$ \\
\hline
\end{tabular}




\subsubsection{Crack patterns}

The crack patterns of the RC beams were achieved using the crack/crushing plot option in NLFEA ANSYS ${ }^{\circ}$. Fig. 18 represents typical cracking signs appearing in FEA for NCS-S0 beam: (a) flexural cracks; (b) compressive cracks; (c) diagonal shear cracks.

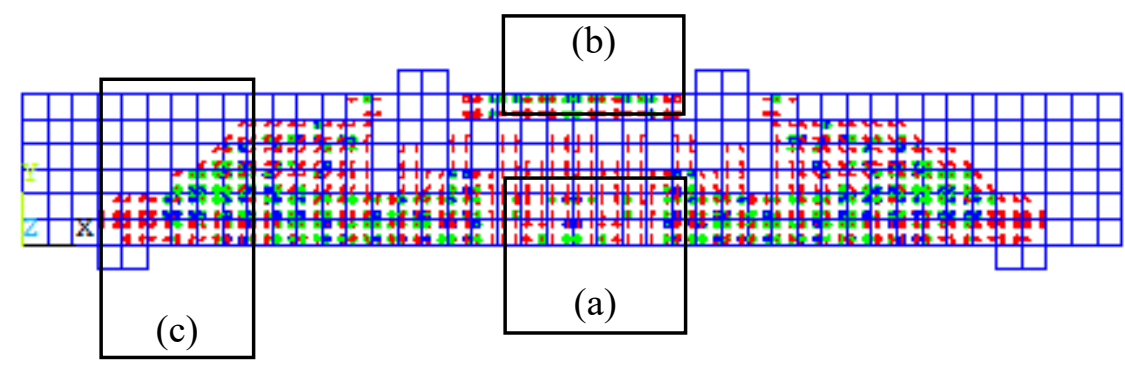

Fig. 18. Typical cracking signs occurring in FEA (NCS-S0).

A cracking signs are shown with a circle outline, they appear when a principal tensile stress exceeds the ultimate tensile strength of the concrete element. The cracking sign appears perpendicular to the direction of the principal tensile stress. The first and second cracks at an integration point are illustrated with a red and green circle outline, respectively (Fig.19 (a)). Crushing occurs when all principal stresses lie outside the failure surface; subsequently, the elastic modulus of the concrete element is set to zero in all directions and the element effectively disappears. Crushing sign is represented with an octahedron outline (Fig. 19 (b)) [44].

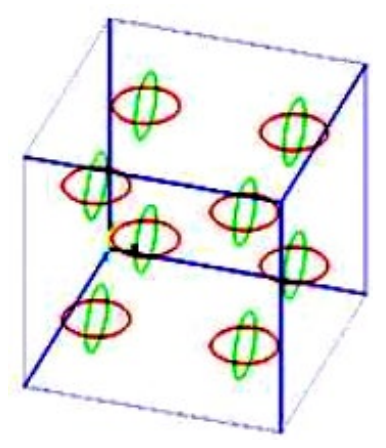

(a)

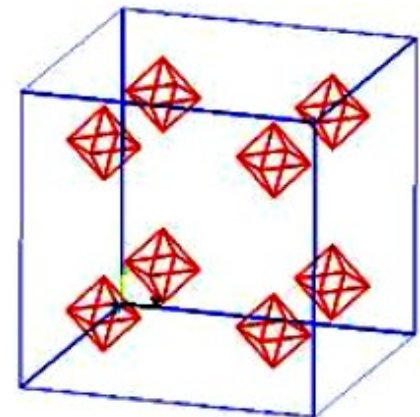

(b)

Fig. 19. Cracking and crushing signs observed in concrete element: (a) cracking (b) crushing.

Fig. 20 displays a comparison between experimental and numerical crack patterns at failure for RC beams. Good agreement of crack patterns observed in experimental investigation with those obtained from the FEA of RC beams can be seen.

From numerical investigation, flexural cracks general begin to manifest early at the mid-span of the beams. When the applied load increases, a vertical flexural crack propagates horizontally from the mid-span to the support. Hereafter, diagonal shear cracks appear at a higher applied load, and as the applied loads continue to increase, an additional diagonal shear and flexural crack appear. Finally, 
compressive cracks appear at nearly the last increment of the applied load. Moreover, the enhancing of the compressive strength of concrete from 32 to $65 \mathrm{MPa}$ increases the number of cracks. Also, the numerical crack number in the beams with transverse reinforcement is greater than that in the beams without stirrups. Furthermore, diagonal crack is approximately inclined at $45^{\circ}$ to the longitudinal axis of the beam. All these findings obtained from numerical approach were also observed during the experimental tests.
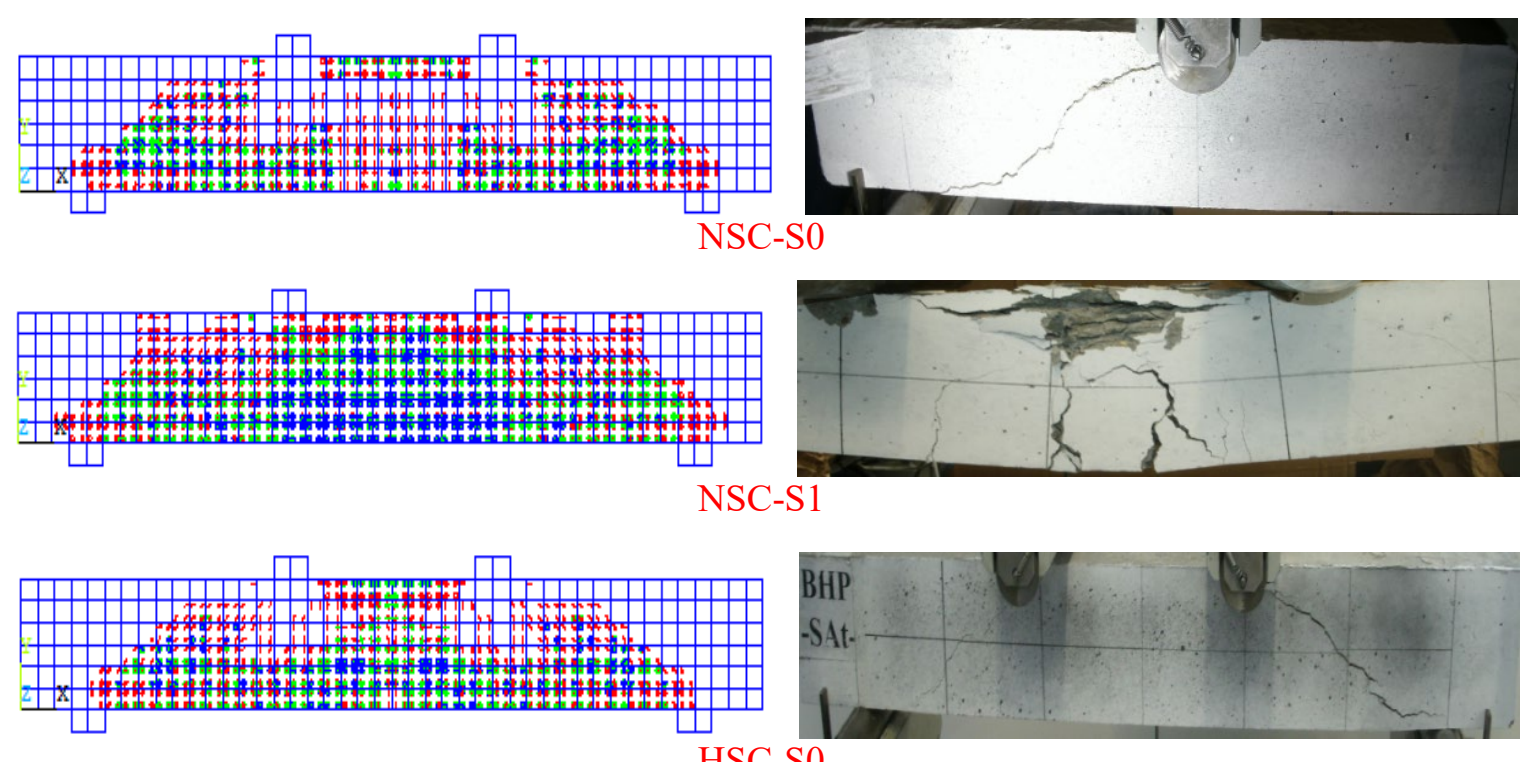

HSC-SO

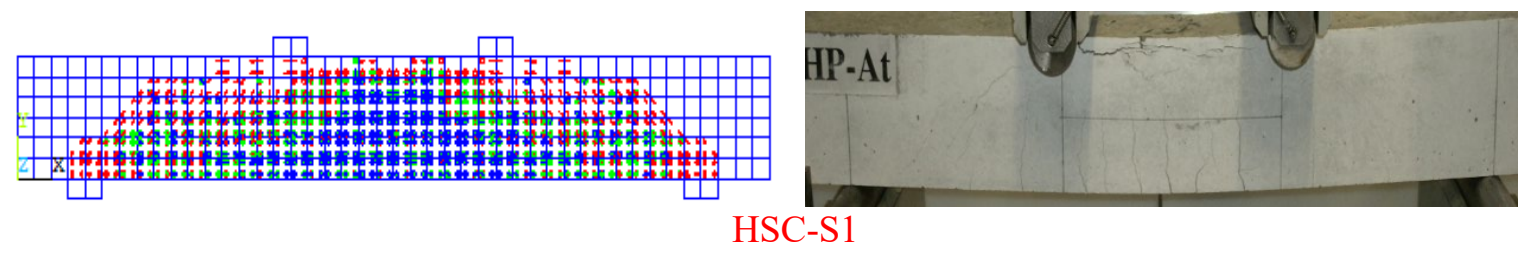

Fig. 20. Crack patterns in RC beams at failure obtained from experimental and numerical study

\subsubsection{Numerical diagonal crack widths}

Nevertheless, the diagonal crack widths are not automatically calculated by ANSYS ${ }^{\odot}$. However, Eq. (8) can be used to calculate the diagonal crack widths (Fig. 21) [50].

$\mathrm{W}=\left(\varepsilon_{1}+\varepsilon_{1}\right) l_{\mathrm{e}}$

where $\mathrm{w}$ is the diagonal crack width $(\mathrm{mm}) ; 1_{\mathrm{e}}$ is the size of the FE of concrete, equal to $20 \mathrm{~mm} ; \varepsilon_{1}$ and $\varepsilon_{2}$ are the left and right strain $(\mu \mathrm{m} / \mathrm{m})$, respectively, predicted by the NLFEA ANSYS ${ }^{\odot}$.

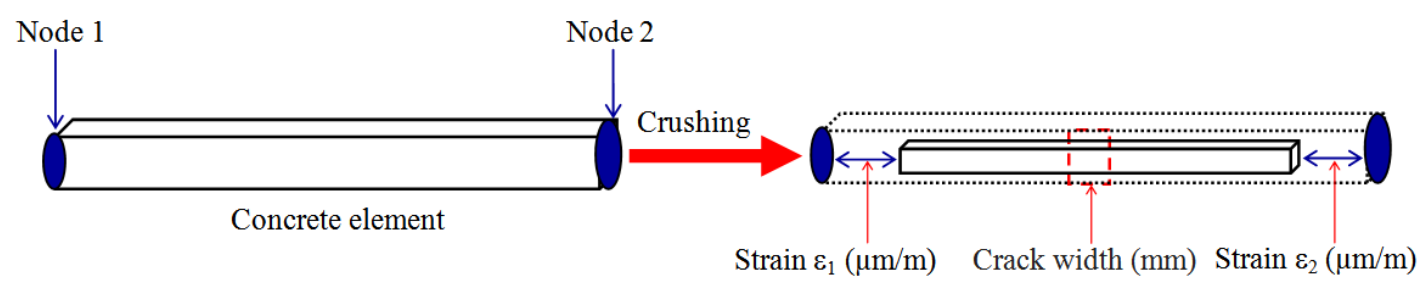

Fig. 21. Procedure of calculation of the diagonal crack width. 
Table 14 compares the maximum diagonal crack widths obtained from FEA using Eq. (8) and experimental data for all beams. The modelled maximum diagonal crack widths are shown to correspond closely to those measured experimentally, with an average ratio of 1.02 , a standard deviation of 0.05 and a coefficient of variation of $4.90 \%$. Thus, the results obtained demonstrate that the developed FE models can be used to better predict the diagonal cracking behaviour of RC beams with and without stirrups.

Table 14. Comparison of experimental and numerical maximum diagonal crack width.

\begin{tabular}{|c|c|c|c|}
\hline Beams & $\begin{array}{l}\text { Experimental diagonal } \\
\text { crack width } \mathrm{w}_{\exp }(\mathrm{mm})\end{array}$ & $\begin{array}{c}\text { Numerical diagonal } \\
\text { crack width } \mathrm{W}_{\text {num }}(\mathrm{mm})\end{array}$ & $\mathrm{W}_{\text {exp }} / \mathrm{W}_{\text {num }}$ \\
\hline NSC-S0 & 0.392 & 0.381 & 1.03 \\
\hline NSC-S1 & 0.124 & 0.131 & 0.95 \\
\hline HSC-S0 & 0.283 & 0.274 & 1.03 \\
\hline HSC-S1 & 0.137 & 0.129 & 1.06 \\
\hline & \multicolumn{2}{|c|}{ Average } & 1.02 \\
\hline & \multicolumn{2}{|c|}{ Standard deviation } & 0.05 \\
\hline & \multicolumn{2}{|c|}{ Coefficient of variation (\%) } & 4.90 \\
\hline
\end{tabular}

\section{Conclusions}

From the results of the present experimental and numerical study on the shear behaviour of RC beams, the following conclusions can be drawn:

- Beams without transverse reinforcement, particularly those made of HSC, exhibit relatively brittle behaviour.

- Changing the concrete compressive strength from 32 to 65 MPa noticeably improves the shear capacity of beams. This improvement ranges between 15 and $20 \%$, and is not proportional to the increase of the compressive strength.

- The mode of failure of the tested beams changes from shear to flexure in the presence of transverse reinforcement, with increases in the ultimate load capacity of NSC and HSC beams.

- The presence of transverse reinforcement efficiently restricts the diagonal crack widths and limits residual stresses after cracking takes place. Diagonal crack formation is delayed and their width is significantly contained; in our investigations, diagonal cracks did not reach the $0.3 \mathrm{~mm}$ serviceability limit width, even at the point of failure. In this sense, diagonal cracks are effectively stitched in HSC beams, compared to those in NSC beams.

-The experimental results are similar to the values extracted from the theoretical predictions of the contribution of concrete to the shear strength of RC beams.

- The contribution of the transverse reinforcement is overestimated by the empirical expression, because it is based on the yielding of the reinforcement, which is not observed even when the beams collapse.

-The FE predicted results of the load-deflection response, the ultimate load, the cracking load, the ultimate deflection and the maximum diagonal crack widths are in close agreement with the 
experimental test data. The difference values between the numerical and experimental values range from -11.08 to $+0.6 \%$, from -2.02 to $-0.52 \%$ and from -13.27 to $-1.01 \%$ for cracking load, for ultimate load and for ultimate mid-span deflection, respectively. The ratio of the predicted to experimental maximum diagonal crack width for the beams ranged between 0.95 and 1.06, with an average value of 1.02 and a C.O.V of $4.9 \%$. Moreover, the crack patterns obtained by FEA are in good agreement with those of laboratory tested beams. Thus, the FE models developed here can be used to predict the shear behaviour of RC beams.

\section{Acknowledgement}

The authors are grateful for the financial support received from the Directorate General for Scientific Research and Technological Development, Algeria.

\section{References}

[1] Tahenni T. Etude de la capacité portante en effort tranchant des poutres en béton armé renforcées en fibres d'acier avec référence particulière aux poutres en béton à hautes performances: Doctoral Thesis, University of Science and Technology Houari Boumediene, Algeria; 2016.

[2] Tahenni T, Chemrouk M, Lecompte T. Effect of steel fibers on the shear behavior of high strength concrete beams. Constr Build Mater. 2016;105:14-28.

[3] Tahenni T, Chemrouk M, Lecompte T. Shear Behavior of High Performance Concrete Beams Using Digital Image Correlation Technique. Singapore: Springer Singapore; 2018. p. 560-70.

[4] Hamrat M, Boulekbache B, Chemrouk M, Amziane S. Shear Behaviour of RC Beams without Stirrups Made of Normal Strength and High Strength Concretes. Adv Struct Eng. 2010;13(1):29-41.

[5] Johnson M, Ramirez J. Minimum shear reinforcement in beams with higher strength concrete. ACI Struct J. 1989;86(4):376-82.

[6] Sarkar S, Adwan O, Bose B. Shear stress contributions and failure mechanisms of high strengh reinforced concrete beams. Mater Struct. 1999;32(2):112.

[7] Taylor H. Investigation of the forces carried across cracks reinforced concrete beams in shear by interlock of aggregate. Technical Report, 42-447, SBN 721007384, Cement and Concrete Association, London. 1970.

[8] Carrasquillo R, Nilson A, FO. S. Properties of high strength concrete subjected to short-term loads. ACI J Proceedings. 1981;78(3):171-8.

[9] Huber T, Huber P, Kollegger J. Influence of aggregate interlock on the shear resistance of reinforced concrete beams without stirrups. Eng Struct. 2019;186:26-42.

[10] Pendyala R, Mendis P. Experimental study on shear strength of high Strength Concrete Beams. ACI Struct J. 2000; 97(4):564-71.

[11] Cladera A, Marí A. Experimental study on high-strength concrete beams failing in shear. Eng Struct. 2005;27(10):1519-27. 
[12] Lowe D, Roy K, Das R, Clifton CG, Lim JBP. Full scale experiments on splitting behaviour of concrete slabs in steel concrete composite beams with shear stud connection. Struct. 2020;23:126-38.

[13] Shokouhi P, Zoëga A, Wiggenhauser H, Fischer G. Surface Wave Velocity-Stress Relationship in Uniaxially Loaded Concrete. ACI Mater J. 2012;109(2):141-8.

[14] Skoček J, Stang H. Application of optical deformation analysis system on wedge splitting test and its inverse analysis. Mater Struct. 2010;43(1):63-72.

[15] Boulekbache B, Hamrat M, Chemrouk M, Amziane S. Failure mechanism of fibre reinforced concrete under splitting test using digital image correlation. Mater Struct. 2015;48(8):2713-26.

[16] Hamrat M, Boulekbache B, Chemrouk M, Amziane S. Flexural cracking behavior of normal strength, high strength and high strength fiber concrete beams, using Digital Image Correlation technique. Constr Build Mater. 2016;106:678-92.

[17] Pereira E, Fischer G, Barros J. Direct assessment of tensile stress-crack opening behavior of Strain Hardening Cementitious Composites (SHCC). Cem Concr Res. 2012;42(6):834-46.

[18] Tahenni T, Chemrouk M, Lecompte T. Steel fibres effects on the flexural cracking behaviour of reinforced high strength concrete beams with particular reference to the major design codes crack width models. Eur J Environ Civ En. 2018:1-20.

[19] Michel A, Solgaard A, Pease B, Geiker M, Stang H, Olesen J. Experimental investigation of the relation between damage at the concrete-steel interface and initiation of reinforcement corrosion in plain and fibre reinforced concrete. Corrosion Science. 2013;77:308-21.

[20] Attari N, Amziane S, Chemrouk M. Flexural strengthening of concrete beams using CFRP, GFRP and hybrid FRP sheets. Constr Build Mater. 2012;37:746-57.

[21] Abu-Obeidah A, Hawileh R, Abdalla J. Finite element analysis of strengthened RC beams in shear with aluminum plates. Comput Struct. 2015;147:36-46.

[22] Banjara NK, Ramanjaneyulu K. Experimental and numerical investigations on the performance evaluation of shear deficient and GFRP strengthened reinforced concrete beams. Constr Build Mater. 2017;137:520-34.

[23] Abed F, El Refai A, Abdalla S. Experimental and finite element investigation of the shear performance of BFRP-RC short beams. Struct. 2019;20:689-701.

[24] Jumaa GB, Yousif AR. Numerical modeling of size effect in shear strength of FRP-reinforced concrete beams. Struct. 2019;20:237-54.

[25] Pachideh G, Gholhaki M, Moshtagh A. On the post-heat performance of cement mortar containing silica fume or Granulated Blast- Furnace Slag. J Build Eng. 2019;24:100757.

[26] EN 12390-3. Testing hardened concrete-Part 3: Compressive strength of test specimens. AFNOR; 2003.

[27] EN 12390-6. Testing hardened concrete — Part 6: Tensile splitting strength of test specimens. AFNOR; 2001. 
[28] ASTM C469. Standard test method for static modulus of elasticity and Poisson's ratio of concrete in compression. ASTM International, West Conshohocken, PA; 2014.

[29] GOM-Aramis. User manuel v6 GOM mbH, Germany. 2007.

[30] Hamrat M, Boulekbache B, Chemrouk M, Amziane S. Effects of the Transverse Reinforcement on the Shear Behaviour of High Strength Concrete Beams. Adv Struct Eng. 2012;15(8):1291-306.

[31] Al Mahmoud F, Boissiere R, Mercier C, Khelil A. Shear behavior of reinforced concrete beams made from recycled coarse and fine aggregates. Struct. 2020;25:660-9.

[32] Zsutty T. Beam shear strength prediction by analysis of existing data. ACI J Proceedings. 1968;65(11):934-51.

[33] Bažant Z, Kim J. Size effect in shear failure of longitudinally reinforced beams. ACI J Proceedings. 1984;81(5):456-68.

[34] Russo G, Puleri G. Stirrup effectiveness in reinforced concrete beams under flexure and shear. ACI Struct J. 1997;94(3):227-38.

[35] Prodromos Z. Shear strength and minimum shear reinforcement of reinforced concrete slender beams. ACI Struct J 2003;100(2):203-14.

[36] Michael P, Evan C, Edward G. Where is shear reinforcement required? review of research results and design procedures. ACI Struct J 2008;105(5):590-600.

[37] Sarsam K, Al-Musawi J. Shear design of high- and normal strength concrete beams with web reinforcement. ACI Struct J 1992;89(6):658-64.

[38] ACI-318-02. Building code requirements for structural concrete and commentary. American Concrete Institute, Farmington Hills, MI, USA. 2002.

[39] BS 8110. Structural use of concrete, Part1, Code of Practice for Design and Construction. British Standards Institution, London. 1997.

[40] Eurocode 2. Design of Concrete Structures- Part 1-1: . General Rules and Rules for Buildings, EN1992-1-1. 2004.

[41] NZS 3101. Part 1 National Standards of New Zealand. : Concrete Structures Standard; Standards New Zealand, Wellington, New Zealand. 2006.

[42] Ritter W. Schweizerische Bauzeitung (Zürich). Die Bauweise Hennebique. 1899;33:59-61.

[43] Mörsch E. Der Eisenbetonbau, seine Anwendung und Theorie, 3ème edition, Me Graw-Hill, New York. 1902.

[44] ANSYS. Release 15.0 Mechanical User's Guide. 2013.

[45] Bouziadi F, Boulekbache B, Haddi A, Djelal C. Experimental and finite element analysis of creep behaviour of steel fibre reinforced high strength concrete beams. Constr Build Mater. 2018;173:10110.

[46] Bouziadi F, Boulekbache B, Haddi A, Djelal C, Hamrat M. Numerical analysis of shrinkage of steel fiber reinforced high-strength concrete subjected to thermal loading. Constr Build Mater. 2018;181:381-93. 
[47] Bouziadi F, Boulekbache B, Haddi A, Hamrat M, Djelal C. Finite element modeling of creep behavior of FRP-externally strengthened reinforced concrete beams. Eng Struct. 2020;204:109908.

[48] Hamrat M, Bouziadi F, Boulekbache B, Daouadji TH, Chergui S, Labed A, et al. Experimental and numerical investigation on the deflection behavior of pre-cracked and repaired reinforced concrete beams with fiber-reinforced polymer. Constr Build Mater. 2020;249:118745.

[49] Lahmar N, Bouziadi F, Boulekbache B, Meziane E-H, Hamrat M, Haddi A, et al. Experimental and finite element analysis of shrinkage of concrete made with recycled coarse aggregates subjected to thermal loading. Constr Build Mater. 2020;247:118564.

[50] Stolarski T, Nakasone Y, Yoshimoto S. Engineering analysis with ANSYS software: Butterworth-Heinemann; 2018. 